\title{
The Key Role of Peroxisomes in Follicular Growth, Oocyte Maturation, Ovulation, and Steroid Biosynthesis
}

\author{
Shan Wang $\mathbb{D}^{1},{ }^{1}$ HaoXuan Yang $\mathbb{D}^{\circ},{ }^{2}$ YongLun Fu $\mathbb{D}^{1},{ }^{1}$ XiaoMing Teng $\mathbb{D}^{1},{ }^{1}$ \\ ChiChiu Wang $\mathbb{1}^{2,3,4,5,6}$ and WenMing $X u \oplus^{2}$ \\ ${ }^{1}$ Department of Assisted Reproductive Medicine, Shanghai First Maternity and Infant Hospital, Tongji University School \\ of Medicine, Shanghai, China \\ ${ }^{2}$ Joint Laboratory of Reproductive Medicine, Sichuan University-The Chinese University of Hong Kong (SCU-CUHK), West China \\ Second University Hospital, Sichuan University, Chengdu, China \\ ${ }^{3}$ Department of Obstetrics and Gynaecology, Faculty of Medicine, The Chinese University of Hong Kong, Hong Kong, China \\ ${ }^{4}$ Reproduction and Development, Li Ka Shing Institute of Health Sciences, The Chinese University of Hong Kong, Hong Kong, China \\ ${ }^{5}$ School of Biomedical Sciences, The Chinese University of Hong Kong, Hong Kong, China \\ ${ }^{6}$ Chinese University of Hong Kong-Sichuan University Joint Laboratory in Reproductive Medicine, The Chinese University of \\ Hong Kong, Hong Kong, China
}

Correspondence should be addressed to WenMing Xu; xuwenming@scu.edu.cn

Received 18 October 2021; Accepted 4 January 2022; Published 3 February 2022

Academic Editor: Anna M. Giudetti

Copyright (c) 2022 Shan Wang et al. This is an open access article distributed under the Creative Commons Attribution License, which permits unrestricted use, distribution, and reproduction in any medium, provided the original work is properly cited.

\begin{abstract}
The absence of peroxisomes can cause disease in the human reproductive system, including the ovaries. The available peroxisomal gene-knockout female mouse models, which exhibit pathological changes in the ovary and reduced fertility, are listed in this review. Our review article provides the first systematic presentation of peroxisomal regulation and its possible functions in the ovary. Our immunofluorescence results reveal that peroxisomes are present in all cell types in the ovary; however, peroxisomes exhibit different numerical abundances and strong heterogeneity in their protein composition among distinct ovarian cell types. The peroxisomal compartment is strongly altered during follicular development and during oocyte maturation, which suggests that peroxisomes play protective roles in oocytes against oxidative stress and lipotoxicity during ovulation and in the survival of oocytes before conception. In addition, the peroxisomal compartment is involved in steroid synthesis, and peroxisomal dysfunction leads to disorder in the sexual hormone production process. However, an understanding of the cellular and molecular mechanisms underlying these physiological and pathological processes is lacking. To date, no effective treatment for peroxisome-related disease has been developed, and only supportive methods are available. Thus, further investigation is needed to resolve peroxisome deficiency in the ovary and eventually promote female fertility.
\end{abstract}

\section{Background}

Peroxisomes, which are ubiquitous cell organelles located in a variety of tissues and organs, participate in many critical metabolic functions in humans, such as lipid metabolism, oxidative metabolic reactions, and cholesterol and plasmalogen synthesis. The ovary, an important reproductive organ, has two major functions: (1) oocyte maturation and release and (2) production of steroid hormones that are irreplaceable for folliculogenesis, menstruation cycle, sex gonad development, and maintenance of the function of the female reproductive tract [1].

Peroxisomes were first discovered by Sharma et al. in the ovary [2]. The peroxisomal enzyme catalase, which is located in the peroxisomal matrix, was discovered via $3,3^{\prime}$-diaminobenzidine $(\mathrm{DAB})$ labelling and electron microscopic analysis of the mouse ovary. In comparison with classical peroxisomes, peroxisomes in the ovary are smaller in size and lack nucleoids; therefore, these organelles are called microperoxisomes [3]. Unlike peroxisomes in the liver, 
which are terminally differentiated, peroxisomes in the ovary undergo constant differentiation with each oestrus cycle [4]. Peroxisomal biogenesis disorders, which are also called diseases of the Zellweger spectrum, induce peroxisome deficiency and are characterized by very severe metabolic abnormalities that lead to a plethora of clinical symptoms. The most severe disease is Zellweger syndrome (ZS), which frequently leads to early death in childhood $[5,6]$. The phenotype of children with ZS is typically characterized by severe hypotonia of the body and embryological malformations of the brain cortex, liver, kidney, and genital organs [5-10]. Regarding the reproductive system, male and female patients with ZS exhibit cryptorchism and clitoromegaly, respectively, which means that the testis might be misplaced and underdeveloped in boys and that the size of the clitoris is markedly larger in girls $[11,12]$. This fact suggests that peroxisomal deficiency causes problems in genital organ development and in the oestrogen-androgen balance. However, there is little information regarding peroxisomal function in the female reproductive system, particularly in the ovary. Both the reactive oxygen species (ROS) balance and lipid metabolism are very important for oocyte maturation, ovulation, fertilization, and embryo development. Thus, our review provides the first description and summary of all the current findings related to the roles of peroxisomes in the ovary, and further research is needed for treating diseases of the female reproductive system and enhancing fertility caused by peroxisomal deletion or dysfunction.

\section{Peroxisomal Biogenesis and Metabolic Functions}

2.1. Peroxisomal Biogenesis. The formation of peroxisomes involves three steps, and different peroxins are needed in each step. According to the available data on peroxins, more than 30 PEX genes have been numbered, and different types of peroxins are known to be involved in different peroxisomal biogenetic processes, as follows: (1) peroxisomal membrane formation: PEX3, PEX16, and PEX19; (2) importation of peroxisomal matrix proteins: PEX5 and PEX7; and (3) fission and proliferation of peroxisomes: PEX13, PEX14, and PEX17 $[13,14]$.

2.2. Peroxisomal Metabolic Functions. Peroxisomes mainly participate in three major metabolic functions: (1) involvement in lipid metabolism; (2) maintaining the balance between ROS production and degradation; and (3) playing critical roles in phospholipid, cholesterol, and bile acid biosynthesis. Furthermore, peroxisomes are involved in retinoid and amino acid metabolism.

2.2.1. Peroxisomal Fatty Acid $\beta$-Oxidation. Fatty acid $\beta$-oxidation mainly occurs in mitochondria for ATP generation, but peroxisomes are able to degrade some long-chain and very-long-chain fatty acyl-coenzyme (CoAs), 2-methylbranched fatty acyl-CoAs, long-chain dicarboxylyl-CoAs, and the CoA esters of bile acid intermediates, which cannot be degraded in the mitochondria $[15,16]$. First, fatty acids must be active in CoA derivatives and then imported into peroxisomes by peroxisomal ATP-binding cassette transporters (ABCDs) [16]. Afterwards, fatty acid $\beta$-oxidation occurs via four steps in peroxisomes: (1) oxidation, acyl$\mathrm{CoA}$ is first desaturated to 2-trans-enoyl-CoA via a reaction catalysed by acyl-CoA oxidases (ACOX); (2) hydration, enoyl-CoA is converted to 3-hydroxyacyl-CoA; (3) dehydrogenation, the hydroxyacyl intermediate is dehydrogenated to a 3-ketoacyl-CoA; and (4) thiolytic cleavage, with the help of thiolase and sterol carrier proteins (SCPx), acetyl-CoA is released together with acyl-CoA, which is two carbon atoms shorter than the original acyl-CoA, and then enters the next round of $\beta$-oxidation [15-17]. Steps (2) and (3) are catalysed by a protein called multifunctional protein (MFPs), which exhibits both enoyl-CoA hydratase and 3 hydroxyacyl-CoA dehydrogenase activities [16, 18].

2.2.2. Peroxisomes and ROS Metabolism. ROS include several radical species, e.g., the superoxide anion $(\mathrm{O} 2 \cdot-)$, the hydroxyl radical $(\cdot \mathrm{OH})$, the hydroxyl radical $(\cdot \mathrm{OH})$, and hydrogen peroxide $\left(\mathrm{H}_{2} \mathrm{O}_{2}\right)$, even though these do not possess unpaired electrons. Peroxisomes are the major location where ROS are generated and diminished [19-23]. ROS serve as a double-edged sword for cells and organs: the accumulation of oxidative damage exerts a particular toxic effect on DNA, proteins, and lipids, whereas ROS play a mediating role in a variety of important cellular processes and cell signalling pathways, such as their pivotal role in apoptosis [24, 25].

Catalase is well known as the main detoxifying enzyme that prevents the accumulation of $\mathrm{H}_{2} \mathrm{O}_{2}$ in cells $[26,27]$. After the dismutation reaction from $\mathrm{O}_{2} \cdot-$ to $\mathrm{H}_{2} \mathrm{O}_{2}$ catalysed by SODs, $\mathrm{H}_{2} \mathrm{O}_{2}$ is converted into $\mathrm{H}_{2} \mathrm{O}$ and $\mathrm{O}_{2}$ [28] via a reaction catalysed by catalase [29]. The overexpression of catalase in transgenic mice leads to an extension of their life span [30], whereas the inhibition of catalase activity in the rat liver suppresses peroxisomal $\beta$-oxidation activity [31]. The amount of catalase is significantly reduced in tumours of the liver and other organs [32,33]. Catalase activity is also reported to be decreased under some pathological conditions, such as ischaemia-reperfusion injury. With the exception of catalase, other enzymes located in peroxisomes, such as peroxiredoxin I and V, SOD1, glutathione S-transferase, and epoxide hydrolase, are all able to degrade $\operatorname{ROS}[23,34]$.

2.2.3. Peroxisome and Ether Phospholipid Synthesis. Ether phospholipid biosynthesis consists of three steps. First, glycerone phosphate is converted to acyl-glycerone phosphate (acyl-GNP) via a reaction catalysed by the peroxisomal enzyme glycerone phosphate acyl transferase (GNPAT), and acyl-GNP is then converted to alkylglycerone phosphate (alkyl-GNP) by the peroxisomal enzyme alkylglycerone phosphate synthase (AGPS) [7, 35]. The last step occurs in the endoplasmic reticulum (ER), and the reaction, which produces alkylglycerol-3-phosphate (alkyl-G-3P), is catalysed by the enzyme alkyl/acyl-GNP NAD(P)H oxidoreductase [35].

2.2.4. Peroxisome and Cholesterol Synthesis. 3-Hydroxy-3methylglutaryl coenzyme A (HMG-CoA) reductase, which 
catalyses the rate-limiting step in cholesterol synthesis, is localized not only in the ER but also in peroxisomes [36]. Furthermore, peroxisomes contain enzymes such as isopentenyl diphosphate delta isomerase (IDI1), mevalonate kinase (MVK), phosphomevalonate kinase (PMVK), and mevalonate pyrophosphate decarboxylase (MPD), which convert mevalonate to farnesyl diphosphate (FPP) [37, 38]. Finally, peroxisomes are involved in maintaining cholesterol homeostasis [39].

\section{Materials and Methods}

3.1. Animals. All experimental protocols performed during this research were carried out in complete accordance to the regulatory guidelines of Animal Ethical and Welfare Committee (AEWC) of Sichuan University, China (approval code: AEWC2016, 6 January 2016). In this study, a total of 16 female C57BL6 mice were purchased from Charles River (Bei Jing, China) and keep the light for $12 \mathrm{~h}$ every day. After perfusion fixation, the ovaries were removed and further fixed by immersion in the same fixative overnight. The next day, complete ovaries were paraffin-embedded.

3.2. Immunofluorescence (IF). For the visualization of peroxisomal proteins in the ovaries, PEX14 (1:500, Proteintech, CAT. 10594-1-AP, CHINA), catalase (1:100, Proteintech, CAT. 21260-1-AP, CHINA), and MFP2 (1:100, Invitrogen, CAT. PA582758, USA) were detected by indirect IF. The IF protocol for staining paraffin sections has been well established in our lab. Ovarian sections were first deparaffinized with xylene $(3 \mathrm{x} 5 \mathrm{~min})$, roasted at $60^{\circ} \mathrm{C}$ for $3 \mathrm{~h}$ and rehydrated through a series of ethanol solutions (99\%, 96\%, $80 \%, 70 \%$, and $50 \%$ ethanol, 3 min each step). Thereafter, the sections were digested with trypsin for $9 \mathrm{~min}$ at $37^{\circ} \mathrm{C}$ to achieve better retrieval of peroxisomal antigens and improved accessibility to epitopes. The sections were then treated with $10 \mathrm{mM}$ citrate buffer at $\mathrm{pH} 6.0$ and heated in a microwave for $15 \mathrm{~min}$ at $900 \mathrm{~W}$. The blocking process was performed with $4 \%$ BSA in Tris-buffered saline containing $0.05 \%$ Tween 20 (TBST) for $1 \mathrm{~h}$ at room temperature. After blocking, the sections were incubated with primary antibodies in 1\% BSA in TBST overnight at room temperature and then with fluorochrome-conjugated secondary antibody (1:1000, Invitrogen, CAT. A11037, CHINA) for $1 \mathrm{~h}$. Because the first antibody was from the same source, we used APEX $^{\text {тм }}$ Antibody Labelling Kits (A10468, Invitrogen, USA) to label the other same primary antibody used for double staining. The conjugated primary antibody was incubated for $14 \mathrm{~h}$ at $4^{\circ} \mathrm{C}$, and the secondary antibody was then rinsed with TBST. Negative controls, which were incubated with TBST buffer instead of the primary antibody, were processed at the same time. The nuclei were stained with $20 \mu \mathrm{l}$ of DAPI containing antifluorescence quenching agent (P0131, $5 \mathrm{ml}$, Beyotime) for $10 \mathrm{~min}$ at room temperature. All pictures were obtained using a confocal laser-scanning microscope (CLSM) with an Olympus FV-1000 (40x objectives, Airy 1; averaging 16; setting pixels $2048 \times 2048$ ). The images were saved as tiff files and processed with Adobe Photoshop (Version cc 2017).

\section{Role of Peroxisomes in the Ovary}

4.1. Peroxisome Distribution in the Ovary. To visualize the peroxisome distribution in the ovary, we stained three representative enzymes of peroxisomes: the peroxisomal biogenesis protein PEX14 and the peroxisomal metabolic enzymes catalase and MFP2, which are two marker enzymes involved in oxidative metabolism and lipid oxidation, respectively.

PEX14 is the perfect marker for visualizing peroxisomes in different cell types and organs in morphological studies [40]. Our IF results showed that peroxisomes labelled with PEX14 are numerous at all follicular stages from primordial follicles to tertiary follicles and are present in the oocyte as well as in the surrounding granulosa and theca cells (Figures 1(a)-1(d)). PEX14 revealed the highest abundance of peroxisomes in steroid hormone-producing interstitial cells followed by granulosa lutein cells of the mature corpus luteum and then granulosa and theca cells in developing follicles. This finding is in agreement with a previously published electron microscopic analysis, which revealed that interstitial cells contain more peroxisomes than granulosa cells of tertiary follicles [41]. This phenomenon has been confirmed by both catalase and MFP2 staining. High amounts of peroxisomes in gonadotropic interstitial and luteinized cells are likely needed to promote the initial steps of steroid biosynthesis and endogenous cholesterol synthesis in this cell type.

An important factor influencing oocyte maturation is the management of oxidative stress, a process in which peroxisomal catalase plays a major role. As described in Background, peroxisomes were first discovered in the ovary using its marker enzyme catalase by Böck and colleagues in 1972 [41]. Catalases were first thought to be absent in oocytes of different species [42,43], but later, studies proved that catalase is present in oocytes at a low amount compared with other cell types of follicles [44] and is distributed in the periphery of the oocyte [45]. Our results confirm these previous findings through the use of regular concentrations (Figures 1(e)-1(h)). A longer exposure time and higher concentrations probably need to be used to visualize catalase expression in oocytes. In contrast to catalase, the other investigated peroxisomal enzymes PEX14 and MFP2 are more highly abundant in oocytes; moreover, the amount of PEX14 and MFP2 in oocytes increases during maturation from primary to tertiary follicles (Figures $1(\mathrm{a})-1(\mathrm{~d})$ and 1(i)-1(1)).

We further found that the follicular granulosa cells surrounding oocytes contain very large amounts of catalase (Figures 1(e)-1(h)). Granulosa cells provide nutrients and signalling molecules that regulate the growth and differentiation of oocytes [46]. Communication between oocytes and granulosa cells occurs through gap junctions that are established in primary follicles [47, 48]. It is possible that oocyte-derived $\mathrm{H}_{2} \mathrm{O}_{2}$ is transferred through gap junctions to granulosa cells, where it is degraded by peroxisomal enzymes. ROS detoxification through gap junctions has been demonstrated in haematopoietic stem cells, which transfer ROS to the bone marrow to protect against the oxidative stress generated during haematopoietic regeneration [49]. 


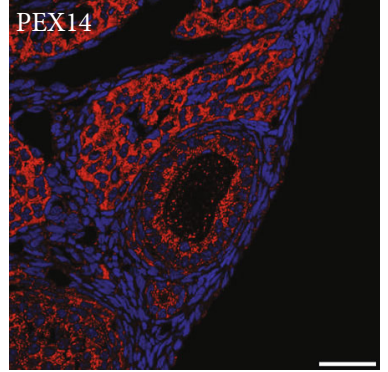

(a)

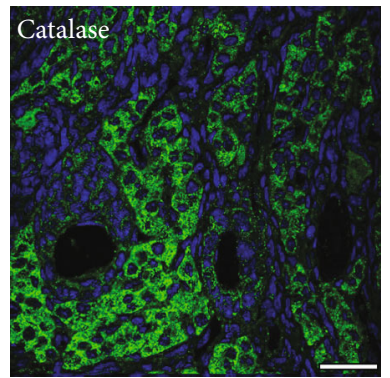

(e)

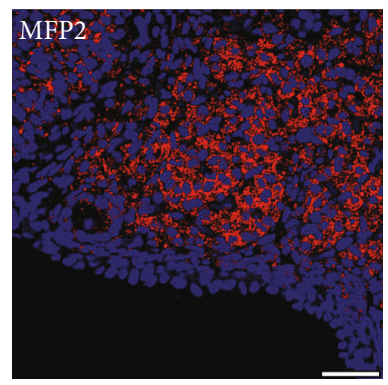

(i)

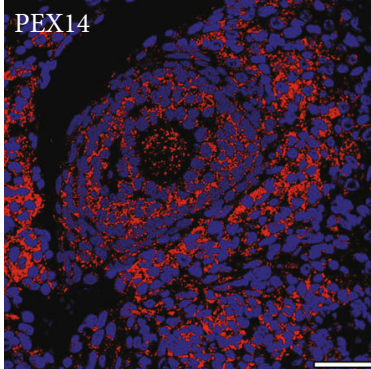

(b)

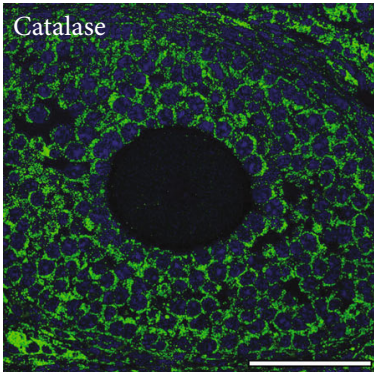

(f)

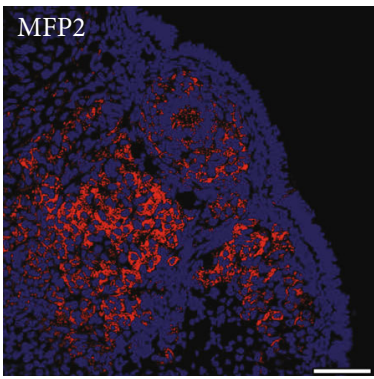

(j)

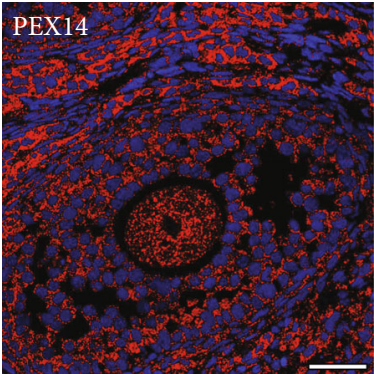

(c)

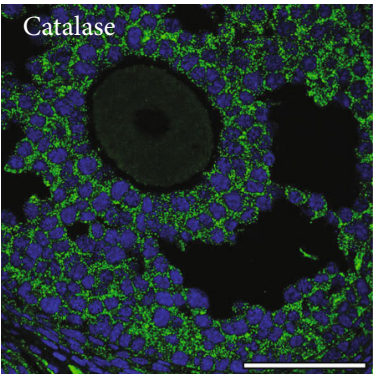

(g)

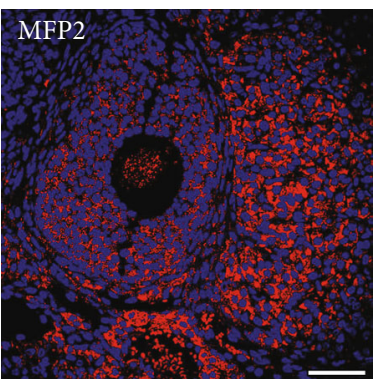

(k)

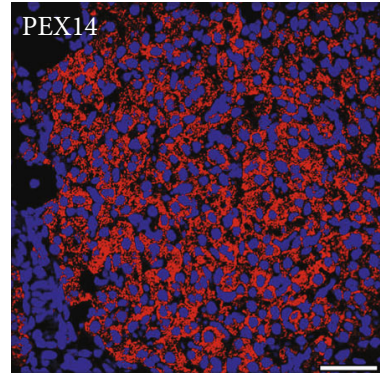

(d)

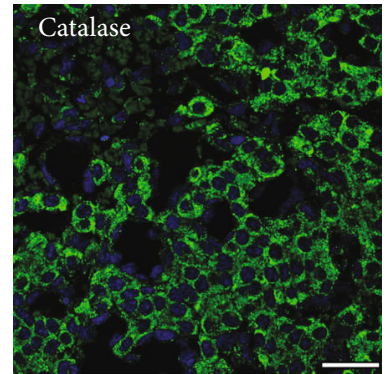

(h)

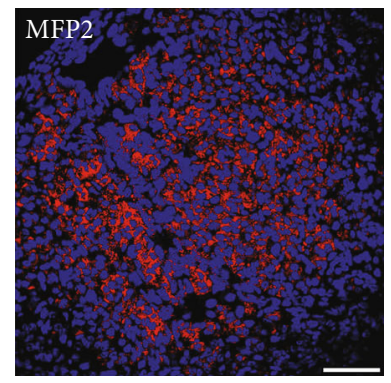

(1)

FIGURE 1: Immunofluorescence analysis of peroxisomal biogenesis proteins in developing follicles and the corpus luteum. Primary, secondary, tertiary follicles, and corpus luteus were stained with PEX14, catalase, and MFP2 antibodies and with DAPI for cell nuclei. Primary follicles are presented in (a, e, i). Secondary follicles are presented in $(b, f, j)$. Tertiary follicles are shown in $(c, g, j)$, and the corpus luteum is presented in $(\mathrm{d}, \mathrm{h}, \mathrm{j})$. Scale bars $=40 \mu \mathrm{m}$.

\subsection{Possible Functions of Peroxisomes during Follicular Development and Oocyte Maturation in the Ovary: ROS and Lipid Metabolism}

4.2.1. Peroxisomal Antioxidative Impacts on Ovarian Functions. Maturation of the oocyte is accompanied by increased ROS within the cells of the ovary, which might be detrimental to folliculogenesis, ovulation, and fertilization $[50,51]$. Excessive ROS can lead to meiotic arrest, oocyte degeneration, development inhibition [52, 53], and zygote apoptosis [54], which leads to reduced fertility [55]. Therefore, several antioxidative enzymes, such as peroxisomal catalase, and molecular antioxidants, such as plasmalogens, function to maintain the cellular redox balance within the ovary $[56,57]$. Previous researches have proved that peroxisomal abundance in the mouse oocytes is relatively constant in different oestrus cycles, but no comparison between different follicular stages was done [58]. Our IF analysis showed that the abundance of the marker protein PEX14 is significantly higher in large tertiary follicles than in primordial, primary, and secondary follicles at the same stage. With the exception of PEX14, peroxisomal MFP2 behaves similarly, which suggests coordinated and regulated proliferation of the peroxisomal compartment during the follicular phase. In contrast, the abundance of peroxisomal enzymes in the ovary during development from primary to tertiary follicles differs among different papers. Previous reports have shown that in rats and swine, the activity of catalase is particularly high in large growing and preovulatory follicles, whereas the abundance of other nonenzymatic and enzymatic ROS scavengers is reduced during follicle development $[59,60]$. In contrast, another study performed in buffalos found that the concentration of catalase does not vary among differently sized follicles [61]. These discrepancies can be explained by species-, oestrus-phase-, and methodologyrelated differences. Behl and Pendley measured the activity of catalase in isolated granulosa cells, Parshad and Guraya measured catalase activity in isolated follicles, and Peterson and Stevenson measured the peroxisomal fraction derived from whole ovaries $[59,62,63]$. Different proteomic analyses have demonstrated the presence of catalase in follicular fluid [64] and found that its activity is higher in large follicles 
[60]; the reason could be that catalases are released from granulosa cells into the follicular fluid in large follicles. Interestingly, the abundance of the antioxidant enzyme family of superoxide dismutase does not vary among granulosa cells of different follicle sizes in cows [65]. In contrast, in the follicular fluid, the activity and amount of SODs are decreased in mature follicles $[60,61,65,66]$, and this decrease may be explained by the demand for ROS in ovulation. In preovulatory follicles, ROS production is upregulated in parallel with cytokines, prostaglandins, proteolytic enzymes, and steroids, which leads to blood flow alterations and eventually to follicle rupture [67]. This process is similar to an acute inflammatory reaction because many inflammatory genes and reagents are induced by the LH surge during this ovulation process [68-70]. In summary, an appropriate ROS concentration is fundamental for providing an appropriate environment for ensuring physiological activation during the oestrus cycle.

In common to the above-discussed studies and in accordance with our theory of the protective role of peroxisomes within ovarian cells, regulation of the oxidative stress level is of key importance during folliculogenesis. Several experiments have shown that catalase is essential for ROS scavenging in the ovary. For example, catalase protects oocyte DNA from oxidative damage during meiosis [71], prevents apoptosis of the oocyte and follicles [62, 72], prevents regression of the corpus luteus during pregnancy [73], contributes to follicle selection [62], and reduces ovary damage during periods of hibernation [74]. In addition to catalase, the peroxisomal enzyme GNPAT plays an indirect role in the control of the oxidative stress levels in cells. Plasmalogens are phospholipids that can be found in any cell as components of the plasma and organellar membranes and are highly susceptible to oxidative stress. Plasmalogens influence membrane dynamics and are particularly abundant in oocytes $[75,76]$. In recent years, plasmalogens have been proposed to function as endogenous antioxidants in ROS trapping and in the protection of cells against the damage resulting from lipid peroxidation [35, 77]. In accordance with the higher requirement for oxidative stress defence at the later stages of oocyte maturation $[59,62,63]$, GNPAT was found to be the most highly abundant in the oocytes of tertiary follicles and is particularly localized in large peroxisomes in the periphery of the oocyte [78]. Taken together, these results strongly indicate that peroxisomes are needed for successful progression through the follicular phase and for the scavenging of ROS during folliculogenesis.

\subsubsection{Peroxisomal Lipid $\beta$-Oxidation Regulation of Ovarian} Functions. In oocytes, nutritional lipids are stored as lipid droplets, which undergo changes in their number, composition, size, and aggregation during follicle maturation [79, 80]. GNPAT is involved in the synthesis of triacylglycerols and other nonether glycerolipids, which are important nutritional lipids [81]. Similar to GNPAT, MFP2, a peroxisomal fatty acid $\beta$-oxidation enzyme [82], and ABCD3 [83], a lipid transporter involved in peroxisomal lipid metabolism displays higher abundance in oocytes of tertiary follicles, which suggests an involvement of peroxisomal lipid metabolism in follicular development of the oocyte during the late stages of folliculogenesis [58]. The mechanism through which the metabolism of lipids is regulated and influences oocyte development remains under investigation but has not been fully clarified. The functional relationship of lipid droplets and mitochondria has been previously postulated due to their close proximity [84]. In oocytes, fatty acids stored within lipid droplets are transferred to mitochondria for ATP generation through $\beta$-oxidation, a process that is increased during oocyte maturation and at the preovulatory phase [85]. In follicles, the nutritional supply and metabolism of lipids provide an important source of ATP for oocyte growth, regulate the fluidity and integrity of the oocyte membrane, determine the viability and developmental competence of oocytes, and influence the composition of the follicular fluid and the efficiency of fertilization $[84,86]$. The inhibition of $\beta$-oxidation has repercussions on acquisition of the developmental competence of the oocyte and fertility by blocking the resumption of meiosis and interfering with nuclear maturation and embryonic development [85, 87]. Nevertheless, most of the available information regarding $\beta$-oxidation in the ovary is related to mitochondrial $\beta$-oxidation, and the function of peroxisomal $\beta$-oxidation in this organ remains to be elucidated. Although peroxisomal $\beta$ oxidation is not directly involved in cellular ATP provision, it shortens long-chain and very-long-chain fatty acids for further metabolization within mitochondria. Furthermore, peroxisomal $\beta$-oxidation degrades a broad spectrum of (toxic) lipid intermediates that cannot be processed by mitochondria, as presented in Background. Therefore, peroxisomes might be responsible for regulation of the homeostasis of fatty acid species such as the long-chain fatty acid linoleic, oleic, stearic, and palmitic acids, which are detrimental for oocyte development [88]. As discussed in the former chapter, ovulation is accompanied by increased production of prostaglandins and cytokines [89] and activation of proteolytic enzymes such as matrix metalloproteinase [90]. Interestingly, peroxisomal $\beta$-oxidation is of major importance for the in vivo chain shortening of prostaglandins [91].

The general regulation of peroxisomes during follicular development is illustrated in Figure 2. However, the molecular mechanisms underlying follicular development have not been fully elucidated, and additional evidence related to the regulation of peroxisomes during this process is needed.

4.3. Possible Function of Peroxisomes in the Corpus Luteum. The corpus luteum is a very important endocrine structure in female ovaries because it can produce a large amount of progesterone and moderate amounts of oestrogen and inhibin A. Moreover, the corpus luteum contributes to maintenance of the early period of pregnancy. When the ovum is not fertilized, the corpus luteum degenerates into fibrous scar tissue called the corpus albicans. In 1972, Böck first described the peroxisome distribution in the mouse ovarian corpus luteum, and the highest level of peroxisomes in the corpus luteum has been found in pregnant females, as demonstrated by the finding that the corpus luteum 


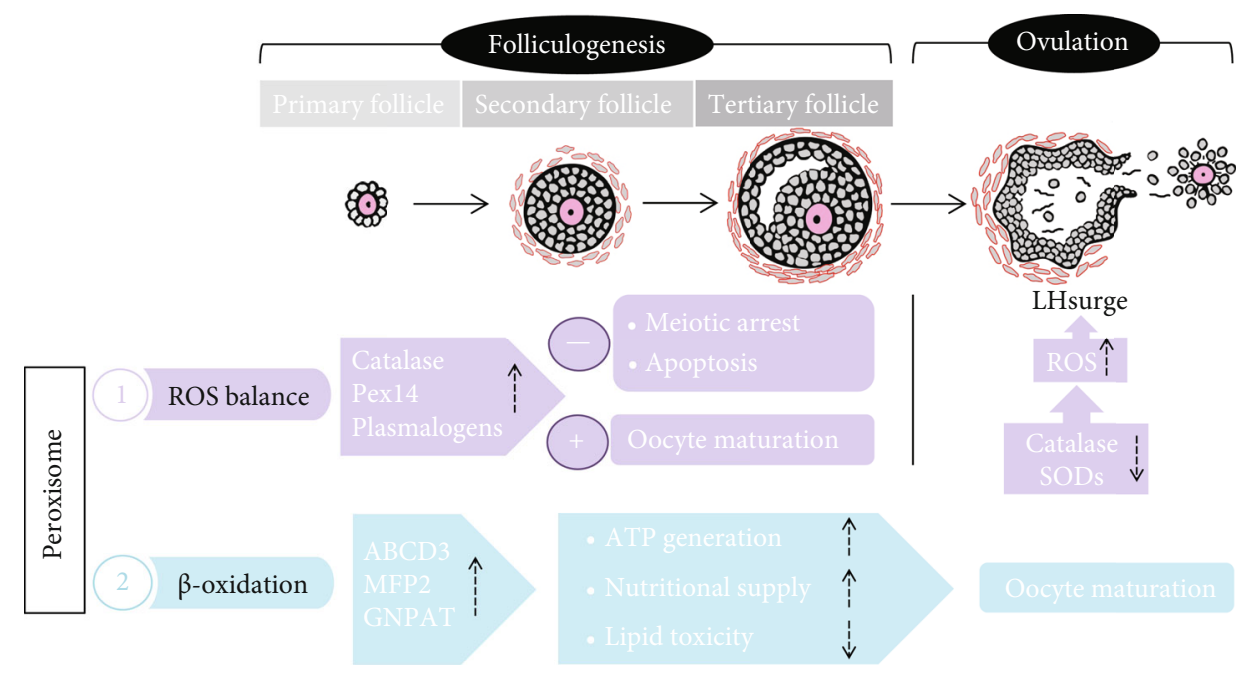

FIGURE 2: Schematic representation of peroxisomal regulation during folliculogenesis. Folliculogenesis is initiated with primordial follicles, which develop into primary follicles, secondary follicles, tertiary follicles, and finally preovulatory follicles. Under an LH surge triggered by oestrogen positive feedback, ovulation occurs for fertilization. This consecutive and synchronized event is accompanied by peroxisomal regulation to maintain the ROS balance and ensure the $\beta$-oxidation reaction. The peroxisomal marker enzyme catalase and peroxisomal biogenesis factor are induced during follicular maturation, whereas SODs are downregulated. A suitable concentration of ROS during different stages of the follicular phase is fundamental for ensuring oocyte development and ovulation. In addition to antioxidation, the peroxisomal $\beta$-oxidative enzymes ABCD3 and MFP2 are induced during follicular maturation and provide sufficient ATP and nutrition for oocyte growth, the selection of dominant oocytes, and the degradation of excessive lipid toxicity to maintain the efficiency of fertilization. The up arrow means "upregulation" while the down arrow stands for "downregulation."

exhibited stronger staining than interstitial cells and markedly stronger staining than granulosa cells of tertiary follicles. In addition, the peroxisome size is slightly larger $(0.2-$ $0.3 \mu \mathrm{m})$ in granulosa lutein cells than in granulosa cells of tertiary follicles $(0.2 \mu \mathrm{m})$, and the peroxisomal profile is markedly less frequent in granulosa cells of tertiary follicles than in granulosa lutein cells [41]. In contrast to granulosa cells in developing follicles, peroxisomes show a very heterogeneous distribution in distinct individual luteinized granulosa cells. This strong heterogeneity was also noted by Böck through catalase staining of the corpus luteum [41]. According to his results, peroxisomes are situated within fields of the smooth endoplasmic reticulum (ER), in the vicinity of lipid droplets and close to mitochondria, which could reflect the organelle interaction and transfer of metabolic intermediators during endogenous cholesterol synthesis and steroid synthesis [41]. The literature indicates that granulosa cells are the specific cell type for oestrogen synthesis because aromatase is only localized in this cell type [92]. Interestingly, aromatase is also very heterogeneously located in the macaque corpus luteum, and the strongly stained cells are interspersed among other weakly stained cells [93]. Accordingly, the heterogeneous peroxisome distribution pattern may reflect different levels of active steroidogenesis in these cells. During steroidogenesis, a large amount of ROS is generated. Therefore, it is not surprising that the peroxisomal antioxidative enzyme catalase is highly abundant in large granulosa lutein cells, as will be discussed in detail in a later section.

4.4. Regulatory Mechanisms of Peroxisomal Genes in the Ovary. The correct progression through the oestrus cycle is timed by the concerted action of gonadotropic hormones, including follicle-stimulating hormone (FSH), luteinizing hormone (LH), and human chorionic gonadotropin (hCG), which are produced in the pituitary gland and placenta. An increasing body of evidence shows that these hormones influence and are influenced by peroxisome proliferatoractivated receptors (PPARs) [94]. PPARs are ligandactivated receptors that regulate disparate metabolic processes, such as lipid and glucose metabolism and cell and organellar proliferation and differentiation $[95,96]$. In particular, these receptors are linked to the proliferation of peroxisomes and the modulation of their ROS and lipid metabolism in various organs $[97,98]$. We speculate that the function of peroxisomes in the ovary is hormonally regulated through the transcription factor class of PPARs.

All three PPARs (PPAR $\alpha, \beta$, and $\gamma$ ) have been detected in the ovaries of different species [99]. In contrast to PPAR $\alpha$ and PPAR $\beta$, which are constantly present throughout the ovarian cycle and folliculogenesis $[99,100]$, the expression of PPAR $\gamma$ increases in preovulatory follicles and markedly decreases after the LH surge (after hCG) $[99,101]$. PPAR $\gamma$, which is the most intensively studied PPAR in the ovary, is detected primarily in granulosa cells and is suggested to influence their function during follicular maturation as well as their intercellular communication with oocytes [102]. The inhibition of PPAR $\gamma$ severely affects the development of oocytes [102]. In 2000, Viergutz et al. indicated that PPAR $\gamma$ plays a role in arresting the cell cycle in lutein cells to maintain their differentiated state [103]. Due to loss of PPAR $\gamma$, one in three females become sterile, and the remaining females become subfertile [104]. These effects may be due to insufficient ovarian function, and this insufficient ovarian 
function is related to the capability of the corpus luteum to produce sufficient progesterone to support the establishment of pregnancy [102]. Indeed, it has been reported that PPARs are involved in the regulation of $17 \beta$-oestradiol and progesterone release by the porcine corpus luteum [105].

\subsection{Roles of Peroxisomes in Ovarian Steroid Synthesis}

4.5.1. Link between Peroxisomal $\beta$-Oxidation and Steroid Synthesis. The first hint that linked peroxisomes with steroid synthesis is the localization of some proteins involved in the steroidogenic pathway in peroxisomes. Steroid synthesis is a complex metabolic process that utilises cholesterol as the obligatory precursor [106]. Cholesterol is either synthesized de novo from acetate via a complex process involving almost 30 different enzymes or obtained from the diet. Interestingly, the presqualene segment of the cholesterol biogenetic pathway is localized in peroxisomes [38, 107-109]. In addition, the key rate-limiting enzyme in cholesterol synthesis, HMG-CoA reductase, is an enzymatic component of peroxisomes $[36,110]$. A mouse model has further proven that peroxisomal plays indispensable roles in cholesterol formation. It has been reported that the cholesterol biogenetic pathway and overall cholesterol regulation are disturbed in the liver of PEX2-knockout mice [37]. The above-described evidence has linked peroxisomes with steroid synthesis through the indispensable precursor "cholesterol."

Moreover, some direct evidence describes the role of peroxisomal enzymes in steroid synthesis. Sterol carrier protein 2 (SCP2) is a peroxisomal $\beta$-oxidation protein involved in peroxisomal $\beta$-oxidation of branched-chain fatty acids and bile acid formation from cholesterol. This protein harbours 3-ketoacyl-CoA thiolase activity in the N-terminal domain and SCP2 in the C-terminal domain $[8,111,112]$ and is enriched in hormone-producing cells and gonads [113-115]. Interestingly, SCP2 serves as the conductor in the cytoplasm for transporting cholesterol into the outer mitochondrial membrane, and after this step, cholesterol is imported into mitochondria via the StAR protein for further steroid synthesis [116-121]. Further evidence has shown that SCP2 is highly expressed in the steroidogenic compartments of the rat ovary and is upregulated after gonadotropin stimulation at both the mRNA and protein levels [122, 123]. Additionally, the peroxisomal enzyme MFP2, also called 17$\beta$-hydroxysteroid dehydrogenase 4 (17 $\beta$-HSD4), catalyses the hydration and dehydrogenation process during $\beta$-oxidation $[15,16]$. This enzyme is reportedly involved in the oxidative step of steroid conversion from oestradiol to estrone. $17 \beta$-HSD 4 is an $80 \mathrm{kDa}$ protein with an N-terminally cleaved enzymatically active fragment of $32 \mathrm{kDa}$ that is capable of conducting the dehydrogenase step not only with $\beta$ oxidation but also with steroids at the $\mathrm{C} 17$ position. This was the first proven enzyme that exhibits dehydrogenase activity with not only 3-hydroxyacyl-CoA derivates of fatty acids but also steroids [124, 125].

The above-described evidence shows the subcellular location of enzymes involved in steroidogenesis and indicates that peroxisomes are directly linked to the hormone production process. To date, very little evidence has been found regarding peroxisomal molecular regulation in ovarian steroidogenesis. In contrast, the regulation of peroxisomes in steroidogenic endocrine regulation has been documented in the testes and adrenal gonads of male animals. In the male adrenal cortex, the number of peroxisomes is upregulated after inhibition of the conversion of cholesterol to pregnenolone [126]. Similarly, the blockage of HMG-CoA reductase with mevilonin or downregulation of the cholesterol levels with nafenopin in serum results in the proliferation of peroxisomes in male rat adrenal gonads [127, 128]. More interestingly, testosterone secretion from rat Leydig cells was observed in parallel with the peroxisome levels by Mendis-Handagama and colleagues [129].

4.5.2. Peroxisomal ROS Production and Antioxidant Regulation during Steroid Synthesis. Many studies have investigated the peroxisomal enzyme catalase in steroidogenic regulation. Catalase shows different distributions among ovarian cycles, and catalase activity is significantly improved in different mammals after gonadotropin stimulation [62, 130-132]. Behl and Pandey further proved that the enhancement of catalase activity parallels oestradiol upregulation after FSH stimulation. Moreover, the degree of the increase was greater in large follicles than in medium and small follicles [62]. FSH promotes follicular development and the selection of dominant follicles [133]; during this stage, oestradiol reaches its highest concentration, and the catalase content increases consistently with the increase in oestradiol after FSH stimulation, which suggests a role for catalase in the selection of dominant follicles and the prevention of atresia. Moreover, catalase activity is positively correlated with the amount of cytochrome P450scc and ferredoxin, which are two components of the steroidogenic electron transport chain in both rat and pig ovaries [134]. In the steroidogenic metabolic pathway, a large amount of ROS is produced [135-137] and then converted via a reaction catalysed by SODs to $\mathrm{H}_{2} \mathrm{O}_{2}[29,138]$ for further detoxification by glutathione peroxidase or catalase. At the midluteal phase, the SOD1 levels are greatly increased after hCG stimulation [139]. Because SOD1 is localized not only in the cytoplasm but also in peroxisomes [140], the extent to which peroxisome-derived SOD1 contributes to the degradation of these oxidative radicals is unclear. After its production, $\mathrm{H}_{2} \mathrm{O}_{2}$ is further degraded by catalase. Thus, catalase, as an ROS cleaner, may act as a protective factor to maintain the balance of ROS concentrations during steroid synthesis and maintain the physiological reaction of hormone synthesis.

4.5.3. Underlying Mechanisms for Steroidogenic Disorder under Peroxisomal Deficiency. The roles of peroxisomes in steroid synthesis were proven in granulosa cell lines by Baumgart-Vogt's laboratory [78], and hormone secretion and steroidogenic proteins are detected after PEX13 knockdown in granulosa tumour cell lines-KK1 cells [141]. PEX13 knockdown can induce whole peroxisomal dysfunction by blocking peroxisomal matrix protein import. In vitro studies have revealed that pregnenolone and progesterone synthesis are strongly downregulated when peroxisomes 
are dysfunctional, and this finding might be explained by the strong reduction of StAR protein after PEX13 knockdown. Similarly, the oestradiol levels are strongly downregulated, which suggests an alteration of $17 \beta$-hydroxysteroid dehydrogenase activity. Additionally, ROS production is enhanced after PEX13 knockdown in KK-1 cells.

ROS are formed during aerobic metabolism, and the physiological content of ROS is important for cellular activities such as cell signalling and ovulation [142-144]. However, excessive amounts of ROS can cause toxic effects on normal ovarian functions and fertility disorders [55, 145]. ROS cleaners, such as SODs, catalase, and glutathione peroxidase (GPX) [146], are increased under peroxisomedeficient conditions, which indicates that peroxisomal deficiency can induce a relative antioxidative response [78]. A similar phenotype has also been observed in Sertoli cellspecific PEX13-knockout mice [147]. Excessive ROS exert negative impacts on hormone synthesis by blocking cholesterol transport into mitochondria in male Leydig cells [148] and female luteal cells [138]. In addition, $\mathrm{H}_{2} \mathrm{O}_{2}$ can inhibit adenylyl cyclase activity and reduce progesterone production [149, 150]. This finding was explained by Diemer and colleagues and is due to dissipation of the mitochondrial membrane potential [151], which is critical for StAR-mediated cholesterol translocation [152]. Interestingly, peroxisomal dysfunction can lead to mitochondrial dysfunction. PEX5-knockout mice exhibit very severe mitochondrial abnormalities in the steroid-producing adrenal cortex [153], and complex III of the mitochondrial respiratory chain is strongly reduced in Sertoli cell-specific PEX13-knockout mice [147]. Two reasons most likely explain the mitochondrial dysfunction observed under peroxisome-disturbed conditions: (1) excessive ROS production induces direct toxic effects and (2) accumulated toxic fatty acids that cannot be degraded by peroxisomes overload the degradation ability of mitochondria. Last but not least, peroxisomal disturbance leads to reduced StAR protein expression, as described above, and the identity of the transcription factor of StAR or the posttranscriptional step that is influenced is worth investigating. The possible mechanism of peroxisomal regulation during steroidogenesis is shown in Figure 3.

\section{Human Disease Caused by Peroxisomal Deficiency}

As described in Background, peroxisomes are indispensable for normal cellular function; therefore, peroxisome dysfunction can lead to serious biochemical abnormalities and result in various clinical symptoms, diseases, and even death. To date, two types of peroxisomal disorders have been identified: peroxisome biogenesis disorders (PBDs) and single peroxisomal metabolic enzyme-related disorders [154]. The biogenesis of peroxisomal membrane protein and matrix protein relies on peroxin (Pex) genes, and mutations in any of the related genes can lead to PBDs [5, 13]. Wellknown PBDs are divided into two groups: ZS disorders (ZSDs) and rhizomelic chondrodysplasia puncta (RCDPs) [37]. ZS is the most severe and well-known disease caused by peroxisomal deficiency, and its manifestation involves severe hypotonia of the body and embryological malformations in the kidney, liver, and central nervous system. ZS can also lead to adrenal cortex degeneration and consequently adrenal deficiency [5-10]. Less severe ZSDs include neonatal adrenoleukodystrophy (NALD) and infantile Refsum disease (IRD) $[5,6]$. Compared with individuals with ZS, patients with NALD and IRD display less severe clinical manifestations. Patients with NALD can survive for more than ten years, and many patients with IRD are expected to survive up to their third decade [155]. Patients with RCDP usually demonstrate skeletal abnormalities, and the underlying cause of RCDP is either mutations of enzymes involved in plasmalogen biosynthesis or problems with peroxisomal targeting signal- (PTS-) 2-specific protein import $[9,155]$.

\section{Peroxisome-Related Dysfunction in the Reproductive System}

ZS is associated with clitoromegaly in girls or cryptorchism in boys, which indicates that peroxisome dysfunction can cause problems in the development of genital organs and an imbalance in androgen-oestrogen secretion [11]. Many of the lines of evidence obtained to date are related to peroxisomal dysfunction in male fertility. Studies have proven that peroxisome metabolism is critical for sexual organs and that peroxisomal dysfunction can result in adrenocortical insufficiency, spermatogenesis defects, and even complete testicular degeneration $[11,12]$. In addition to clinical manifestations, many mouse models have described the negative influence of peroxisomal gene knockout on male reproductive health. For example, ACOX1-deficient mice exhibit reduced amounts of Leydig cells and spermatids [156]. In addition, arrest of spermatogenesis and atrophic testes have been observed in GNPAT-knockout mice [157]. Moreover, the knockout of MFP2 causes fatty acid accumulation in Sertoli cells and seminiferous tubules, an incomplete germinal epithelium and a reduction in elongated spermatids, which results in male infertility [158]. Baumgart-Vogt used a Sertoli cell-specific Pex13-knockout mouse model to investigate peroxisomal function in the testis and found that the mouse model exhibited "Sertoli cell only" syndrome (SCO) [147]; additionally, strong accumulation of peroxisomemetabolized fatty acids (VLCFAs, phytanic acid, and pristanic acid) and neutral lipids are observed in the testis, and large intratubular vacuoles are observed in seminiferous tubules [147]. All of these findings are consistent with testicular disorders often found in patients with ZS and/or XALD/AMN.

Compared with peroxisomal insufficiency-related pathologies related to male reproductive health, almost no studies have investigated the pathological alterations in the female ovary. According to the literature, only two papers describe peroxisomal gene-knockout female mice. Rodemer et al. found a reduced ovary size in GNPAT-knockout mice, and the number of secondary and tertiary follicles and corpora lutea was reduced, but no influence was observed on intact follicles [157]. Another study found that female 


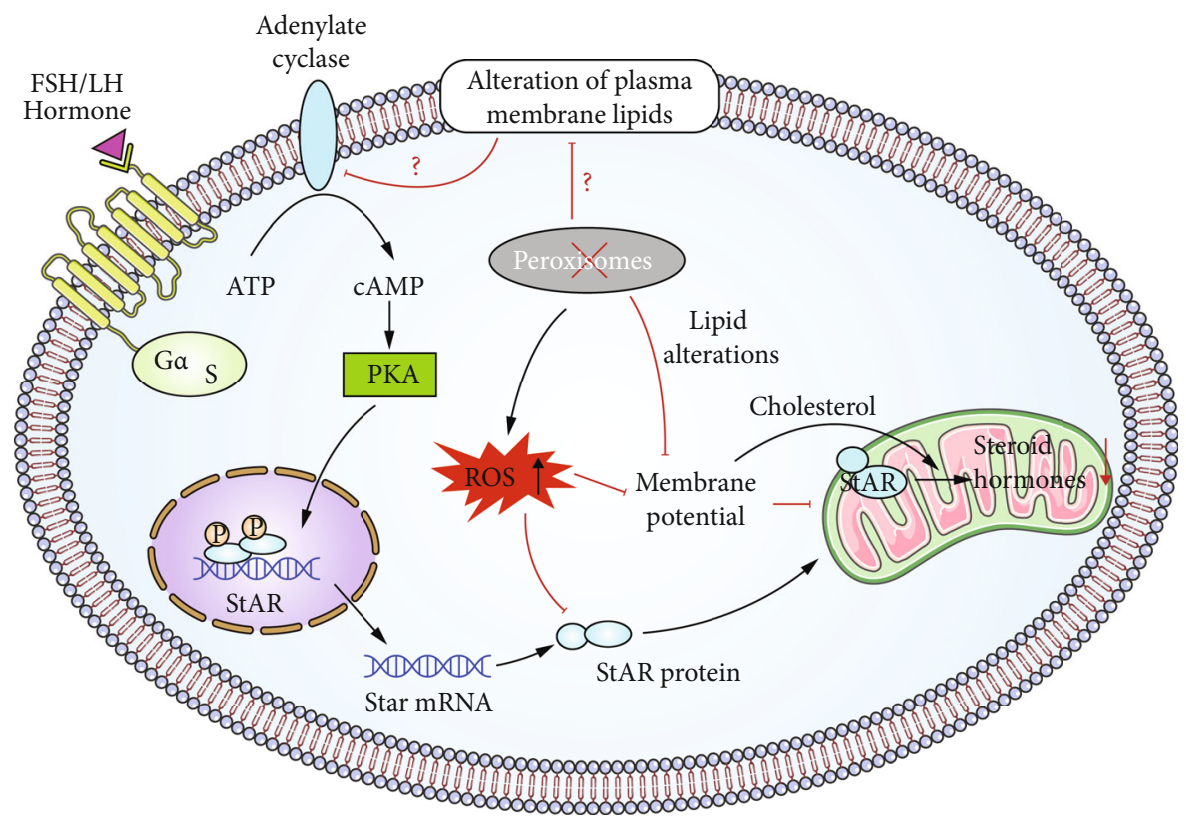

FIgURe 3: Possible mechanism of peroxisomal regulation during steroidogenesis. According to the literature, the steroidogenic pathway is disturbed under peroxisomal-deficient conditions. The underlying mechanism may at least partly involve inhibition of the rate-limiting enzyme StAR. Excessive oxidative stress caused by peroxisomal deficiency can directly lead to the inhibition of steroid synthesis; moreover, the mitochondrial membrane potential is disturbed under peroxisomal-deficient conditions, which deteriorates StAR-mediated cholesterol transport. The specific molecular mechanism of StAR inhibition needs to be clarified in the future. Additionally, the lipid structure and lipid composition of the cell membrane are closely related to the activity of adenylyl cyclase (AC) and G protein-coupled receptor signalling. We hypothesize that peroxisomes may be involved in upstream cell signalling for hormone production by regulating the membrane composition of steroidogenic cells. Red line stands for "inhibit" while black line means "promote."

ACOX-knockout mice present smaller ovaries and infertility [159]. However, these two papers only describe the phenotypes; the underlying molecular mechanism remains to be clarified in the future.

\section{Possible Therapy against Peroxisome- Related Disease}

Peroxisomal deficiency-caused ZSDs exhibit very severe symptoms in the neonatal period and later in adolescence or adulthood and frequently leads to early death in childhood. At present, no curative therapy has been developed, and only supportive care is available. Through peroxisomal $\beta$-oxidation, tetracosahexaenoic acid is converted to docosahexaenoic acid (DHA), a long-chain polyunsaturated fatty acid that is important for retinal and brain function [160, 161]. Patients with ZSDs have low levels of DHA in membranes of erythrocytes, and DHA supplementation may be helpful for these patients, but this finding remains debated [162-164]. Lorenzo's oil leads to lower VLCFAs in plasma and may helpful for patients with X-ALD [165-167] but is useless for disease progression [168, 169]. Plasmalogens are critical for cell membrane formation, indeed patients with ZSD, that usually have low amount of plasmalogens, present problems in cell membrane formation $[170,171]$. It has been proven that supplementation with precursors of plasmalogens (batyl alcohol) can increase the erythrocyte plasmalogen levels and improve clinical symptoms in some patients [172-174]. In addition, some ongoing clinical trials have identified several compounds that can stimulate peroxisomal biogenesis and function in vitro [175-179]. Hopefully, these compounds will be administered to patients to improve peroxisomal function in the future. Moreover, gene therapy has been introduced but still needs to be verified in human trials $[180,181]$. Orthotopic liver transplantation has been applied to one 6-month-old patient with ZSD, and hepatocyte transplantation was administered to another 4-year-old patient $[182,183]$. This therapy is helpful for decreasing the concentrations of VLCFAs and pipecolic acid and improves the bile acid profiles in these patients. Unfortunately, the effects of peroxisomal therapy on ovarian functions have not been investigated. According to our review, supplementation with precursors of plasmalogens may contribute to improving oocyte quality by ensuring membrane function and trapping ROS.

As described in the literature, only treatments against oxidative conditions derived from peroxisomal deficiency have been developed. Antioxidant supplementation can reduce oxidative stress caused by excessive ROS in humans [55]. Both enzymatic and nonenzymatic antioxidants have been proven to be helpful for the removal of excessive ROS [55]. It has been reported that antioxidant supplementation is beneficial for the oocyte quality in mouse [184]. In addition, the antioxidant melatonin, a very important naturally produced antioxidant in mammals, is able to prevent the ROS-mediated deterioration of the oocyte quality in rats $[185,186]$ and humans $[187,188]$. In addition to melatonin, resveratrol can improve the number and quality of oocytes 
of mice and protect against the reduction of fertility observed with reproductive ageing [189], and it has also been proved that resveratrol plays a protective role against premature ovarian failure (POF) and prompts female germline stem cell survival in mice [190]. Jiang et al. have shown that the possible mechanism through which ROS induces POF involves the suppression of telomerase reverse transcriptase (TERT) activity [191]. Nonenzymatic antioxidants such as vitamins A, C [189], and E [192, 193] are reportedly able to reduce the oxidative stress marker in women with endometriosis but have no effects on the fertilization rate [193]. N-acetyl-cysteine (NAC) is able to increase the intracellular GSH concentrations and/or directly scavenge free radicals [194, 195]. After the administration of a combination of NAC and folic acid, patients with unexplained recurrent pregnancy loss achieve better outcomes [196]. More studies are needed to investigate the effects of antioxidant supplementation as a possible treatment therapy for these patients. The daily intake of fresh green vegetables, fruits, antioxidant-rich legumes, and plant products that contain high levels of antioxidants may be beneficial for reducing ROS [197]. The administration of additional antioxidants to neutralize excessive ROS production caused by peroxisomal deficiency may be an effective therapy in the future because the ROS balance is critical for follicular maturation, oocyte development, and mitochondria function involving hormone production.

\section{Conclusion}

Due to the increase in the infertility rate observed in recent years, researchers have shown growing interest in investigating the regulation of ovarian function and oocyte maturation. The deterioration of oocyte quality will lead to an increased probability of aneuploidy and miscarriage. The redox balance is closely related to female subfertility and infertility. With the exception of ROS and antioxidants, lipid regulation and metabolism also play indispensable roles on oocyte maturation, ovulation, fertilization, and embryo development. In this review, we thoroughly present the expression and regulation of some major peroxisomal antioxidants and $\beta$-oxidative enzymes during follicular development, oocyte maturation, ovulation, corpus luteum function, and steroidogenesis. This review provides the first systematic analysis of the role of peroxisomes in ovarian functions. However, the molecular mechanism underlying these roles has not been fully investigated, and further studies are needed to elucidate the specific regulatory pathway through which peroxisomes affect ovarian function, which would provide further insights for the treatment of female infertility in vivo.

\section{Additional Points}

Summary Sentence. Peroxisomes are strongly involved in ovarian follicular growth, oocyte maturation, ovulation, and steroid biosynthesis to maintain normal fertilization

\section{Disclosure}

The funders had no role in study design, data collection and analysis, decision to publish, or preparation of the manuscript.

\section{Conflicts of Interest}

The authors declare that there are no conflicts of interest regarding the publication of this paper.

\section{Authors' Contributions}

Shan Wang and HaoXuan Yang contributed equally to this work.

\section{Acknowledgments}

This review is based on Dr. Shan Wang's PhD dissertation. This work was supported by the Natural Sciences Foundation of China (81901435), the Theme-based Research Scheme (T13-602/21-N), the Collaborative Research Fund (C5045-20EF), and the General Research Fund (14122021) from Research Grant Council.

\section{References}

[1] E. A. McGee and A. J. Hsueh, "Initial and cyclic recruitment of ovarian follicles," Endocrine Reviews, vol. 21, no. 2, pp. 200-214, 2000.

[2] R. Sharma, K. R. Biedenharn, J. M. Fedor, and A. Agarwal, "Lifestyle factors and reproductive health: taking control of your fertility," Reproductive Biology and Endocrinology, vol. 11, no. 1, 2013.

[3] A. B. Novikoff and P. M. Novikoff, "Microperoxisomes," The Journal of Histochemistry and Cytochemistry, vol. 21, no. 11, pp. 963-966, 1973.

[4] D. Singh and R. S. Pandey, "Changes in catalase activity and hydrogen peroxide level in rat ovary during estrous cycle and induction of catalase in rat ovary by estradiol-17 beta," Indian Journal of Experimental Biology, vol. 36, no. 4, pp. 421-423, 1998.

[5] S. J. Gould and D. Valle, "Peroxisome biogenesis disorders: genetics and cell biology," Trends in Genetics, vol. 16, no. 8, pp. 340-345, 2000.

[6] H. W. Moser, "Genotype-phenotype correlations in disorders of peroxisome biogenesis," Molecular Genetics and Metabolism, vol. 68, no. 2, pp. 316-327, 1999.

[7] R. J. Wanders, "Peroxisomes, lipid metabolism, and peroxisomal disorders," Molecular Genetics and Metabolism, vol. 83, no. 1-2, pp. 16-27, 2004.

[8] R. J. Wanders and J. M. Tager, "Lipid metabolism in peroxisomes in relation to human disease," Molecular Aspects of Medicine, vol. 19, no. 2, pp. 69-154, 1998.

[9] P. B. Lazarow, "Peroxisome Structure, Function, and Biogenesis-Human Patients and Yeast Mutants Show Strikingly Similar Defects in Peroxisome Biogenesis," Journal of Neuropathology and Experimental Neurology, vol. 54, 1995.

[10] H. W. Moser, J. M. Powers, and K. D. Smith, "Adrenoleukodystrophy: molecular genetics, pathology, and Lorenzo's oil," Brain Pathology, vol. 5, no. 3, pp. 259-266, 1995. 
[11] J. M. Powers, “Adreno-leukodystrophy (adreno-testiculoleukomyelo-neuropathic-complex)," Clinical Neuropathology, vol. 4, no. 5, pp. 181-199, 1985.

[12] J. M. Powers and H. H. Schaumburg, "The testis in adrenoleukodystrophy," The American Journal of Pathology, vol. 102, no. 1, pp. 90-98, 1981.

[13] B. Distel, R. Erdmann, S. J. Gould et al., "A unified nomenclature for peroxisome biogenesis factors," The Journal of Cell Biology, vol. 135, no. 1, pp. 1-3, 1996.

[14] J. J. Smith and J. D. Aitchison, "Regulation of peroxisome dynamics," Current Opinion in Cell Biology, vol. 21, no. 1, pp. 119-126, 2009.

[15] T. Hashimoto, "Peroxisomal ?-Oxidation: enzymology and molecular biology," Annals of the New York Academy of Sciences, vol. 804, no. 1 Peroxisomes, pp. 86-98, 1996.

[16] T. Hashimoto, "Peroxisomal beta-oxidation enzymes," Neurochemical Research, vol. 24, no. 4, pp. 551-563, 1999.

[17] P. B. Lazarow and C. De Duve, "A fatty acyl-CoA oxidizing system in rat liver peroxisomes; enhancement by clofibrate, a hypolipidemic drug," Proceedings of the National Academy of Sciences of the United States of America, vol. 73, no. 6, pp. 2043-2046, 1976.

[18] D. L. Kroetz, P. Yook, P. Costet, P. Bianchi, and T. Pineau, "Peroxisome Proliferator-activated Receptor $\alpha$ Controls the Hepatic CYP4A Induction Adaptive Response to Starvation and Diabetes," The Journal of Biological Chemistry, vol. 273, no. 47, pp. 31581-31589, 1998.

[19] C. De Duve and P. Baudhuin, "Peroxisomes (microbodies and related particles)," Physiological Reviews, vol. 46, no. 2, pp. 323-357, 1966.

[20] B. M. Elliott, N. J. Dodd, and C. R. Elcombe, "Increased hydroxyl radical production in liver peroxisomal fractions from rats treated with peroxisome proliferators," Carcinogenesis, vol. 7, no. 5, 1986.

[21] R. M. Zwacka, A. Reuter, E. Pfaff et al., “The glomerulosclerosis gene Mpv17 encodes a peroxisomal protein producing reactive oxygen species," The EMBO Journal, vol. 13, no. 21, pp. 5129-5134, 1994.

[22] D. B. Stolz, R. Zamora, Y. Vodovotz et al., "Peroxisomal localization of inducible nitric oxide synthase in hepatocytes," Hepatology, vol. 36, no. 1, pp. 81-93, 2002.

[23] M. Fransen, M. Nordgren, B. Wang, and O. Apanasets, "Role of peroxisomes in ROS/RNS-metabolism: implications for human disease," Biochimica et Biophysica Acta, vol. 1822, no. 9, pp. 1363-1373, 2012.

[24] W. Droge, "Oxidative stress and aging," Advances in Experimental Medicine and Biology, vol. 543, pp. 191-200, 2003.

[25] M. Saran, "Review," Free Radical Research, vol. 37, no. 10, pp. 1045-1059, 2003.

[26] N. Oshino, R. Oshino, and B. Chance, "The characteristics of the "peroxidatic" reaction of catalase in ethanol oxidation," The Biochemical Journal, vol. 131, no. 3, pp. 555-563, 1973.

[27] A. G. Siraki, J. Pourahmad, T. S. Chan, S. Khan, and P. J. O’Brien, "Endogenous and endobiotic induced reactive oxygen species formation by isolated hepatocytes," Free Radical Biology \& Medicine, vol. 32, no. 1, pp. 2-10, 2002.

[28] B. Chance, H. Sies, and A. Boveris, "Hydroperoxide metabolism in mammalian organs," Physiological Reviews, vol. 59, no. 3, pp. 527-605, 1979.

[29] J. M. McCord, B. B. Keele Jr., and I. Fridovich, “An enzymebased theory of obligate anaerobiosis: the physiological func- tion of superoxide dismutase," Proceedings of the National Academy of Sciences of the United States of America, vol. 68, no. 5, pp. 1024-1027, 1971.

[30] S. E. Schriner, N. J. Linford, G. M. Martin et al., "Extension of murine life span by overexpression of catalase targeted to mitochondria," Science, vol. 308, no. 5730, pp. 1909-1911, 2005.

[31] H. Fumie and H. Hidenori, "Significance of catalase in peroxisomal fatty acyl-CoA $\beta$-oxidation," Biochimica et Biophysica Acta, vol. 921, no. 1, pp. 142-150, 1987.

[32] J. A. Litwin, K. Beier, A. Volkl, W. J. Hofmann, and H. D. Fahimi, "Immunocytochemical investigation of catalase and peroxisomal lipid $\beta$-oxidation enzymes in human hepatocellular tumors and liver cirrhosis," Virchows Archiv, vol. 435, no. 5, pp. 486-495, 1999.

[33] C. Lauer, A. Volkl, S. Riedl, H. D. Fahimi, and K. Beier, "Impairment of peroxisomal biogenesis in human colon carcinoma," Carcinogenesis, vol. 20, no. 6, pp. 985-989, 1999.

[34] V. D. Antonenkov, S. Grunau, S. Ohlmeier, and J. K. Hiltunen, "Peroxisomes are oxidative organelles," Antioxidants \& Redox Signaling, vol. 13, no. 4, pp. 525-537, 2010.

[35] P. Brites, H. R. Waterham, and R. J. Wanders, "Functions and biosynthesis of plasmalogens in health and disease," Biochimica et Biophysica Acta, vol. 1636, no. 2-3, pp. 219-231, 2004.

[36] G. A. Keller, M. C. Barton, D. J. Shapiro, and S. J. Singer, "3Hydroxy-3-methylglutaryl-coenzyme A reductase is present in peroxisomes in normal rat liver cells," Proceedings of the National Academy of Sciences of the United States of America, vol. 82, no. 3, pp. 770-774, 1985.

[37] W. J. Kovacs, L. M. Olivier, and S. K. Krisans, "Central role of peroxisomes in isoprenoid biosynthesis," Progress in Lipid Research, vol. 41, no. 5, pp. 369-391, 2002.

[38] W. J. Kovacs, K. N. Tape, J. E. Shackelford et al., "Localization of the pre-squalene segment of the isoprenoid biosynthetic pathway in mammalian peroxisomes," Histochemistry and Cell Biology, vol. 127, no. 3, pp. 273-290, 2007.

[39] W. J. Kovacs, J. E. Shackelford, K. N. Tape et al., "Disturbed cholesterol homeostasis in a Peroxisome-DeficientPEX2Knockout mouse model," Molecular and Cellular Biology, vol. 24, no. 1, pp. 1-13, 2004.

[40] P. Grant, B. Ahlemeyer, S. Karnati et al., "The biogenesis protein PEX14 is an optimal marker for the identification and localization of peroxisomes in different cell types, tissues, and species in morphological studies," Histochemistry and Cell Biology, vol. 140, no. 4, pp. 423-442, 2013.

[41] P. Bock, "Peroxisomes in the mouse ovary," Zeitschrift für Zellforschung und Mikroskopische Anatomie, vol. 133, no. 1, pp. 131-140, 1972.

[42] S. El Mouatassim, P. Guerin, and Y. Menezo, "Expression of genes encoding antioxidant enzymes in human and mouse oocytes during the final stages of maturation," Molecular Human Reproduction, vol. 5, no. 8, pp. 720-725, 1999.

[43] F. Roels, T. Tytgat, S. Beken et al., "Peroxisome mosaics in the liver of patients and the regulation of peroxisome expression in rat hepatocyte cultures," Annals of the New York Academy of Sciences, vol. 804, no. 1 Peroxisomes, pp. 502-515, 1996.

[44] M. B. Harvey, M. Y. Arcellana-Panlilio, X. Zhang, G. A. Schultz, and A. J. Watson, "Expression of genes encoding antioxidant enzymes in preimplantation mouse and cow embryos and primary bovine oviduct cultures employed for embryo Coculture1," Biology of Reproduction, vol. 53, no. 3, pp. 532-540, 1995. 
[45] C. Figueroa, M. E. Kawada, L. P. Véliz et al., "Peroxisomal proteins in rat gametes," Cell Biochemistry and Biophysics, vol. 32, no. 1-3, pp. 259-268, 2000.

[46] J. J. Eppig, "Intercommunication between mammalian oocytes and companion somatic cells," BioEssays, vol. 13, no. 11, pp. 569-574, 1991.

[47] E. C. Beyer, "Gap junctions," International Review of Cytology, vol. 137C, pp. 1-37, 1993.

[48] N. M. Kumar and N. B. Gilula, "The gap junction communication channel," Cell, vol. 84, no. 3, pp. 381-388, 1996.

[49] E. Taniguchi Ishikawa, D. Gonzalez-Nieto, G. Ghiaur et al., "Connexin-43 prevents hematopoietic stem cell senescence through transfer of reactive oxygen species to bone marrow stromal cells," Proceedings of the National Academy of Sciences of the United States of America, vol. 109, no. 23, pp. 9071-9076, 2012.

[50] K. H. Al-Gubory, P. A. Fowler, and C. Garrel, "The roles of cellular reactive oxygen species, oxidative stress and antioxidants in pregnancy outcomes," The International Journal of Biochemistry \& Cell Biology, vol. 42, no. 10, pp. 1634-1650, 2010.

[51] S. Wang, G. He, M. Chen, T. Zuo, W. Xu, and X. Liu, "The role of antioxidant enzymes in the ovaries," Oxidative Medicine and Cellular Longevity, vol. 2017, Article ID 4371714, 14 pages, 2017.

[52] P. Guerin, S. El Mouatassim, and Y. Menezo, "Oxidative stress and protection against reactive oxygen species in the pre-implantation embryo and its surroundings," Human Reproduction Update, vol. 7, no. 2, pp. 175-189, 2001.

[53] H. Tatemoto, N. Sakurai, and N. Muto, "Protection of porcine oocytes against apoptotic cell death caused by oxidative stress during in vitro maturation: role of cumulus Cells1," Biology of Reproduction, vol. 63, no. 3, pp. 805-810, 2000.

[54] L. Liu, J. R. Trimarchi, and D. L. Keefe, "Involvement of mitochondria in oxidative stress-induced cell death in mouse Zygotes1," Biology of Reproduction, vol. 62, no. 6, pp. 17451753, 2000.

[55] A. Agarwal, A. Aponte-Mellado, B. J. Premkumar, A. Shaman, and S. Gupta, "The effects of oxidative stress on female reproduction: a review," Reproductive Biology and Endocrinology, vol. 10, no. 1, p. 49, 2012.

[56] P. J. Devine, S. D. Perreault, and U. Luderer, "Roles of reactive oxygen species and antioxidants in ovarian Toxicity1," Biology of Reproduction, vol. 86, no. 2, p. 27, 2012.

[57] J. Fujii, Y. Iuchi, and F. Okada, "Fundamental roles of reactive oxygen species and protective mechanisms in the female reproductive system," Reproductive Biology and Endocrinology, vol. 3, no. 1, 2005.

[58] E. M. F. B. Distler, Peroxisomen im murinen ovar, Justus Liebig University Giessen, 2015.

[59] S. L. Peterson and P. M. Stevenson, "Changes in catalase activity and concentration during ovarian development and differentiation," Biochimica et Biophysica Acta (BBA)-Molecular Cell Research, vol. 1135, no. 2, pp. 207-214, 1992.

[60] G. Basini, B. Simona, S. E. Santini, and F. Grasselli, "Reactive oxygen species and anti-oxidant defences in swine follicular fluids," Reproduction, Fertility, and Development, vol. 20, no. 2, pp. 269-274, 2008.

[61] K. H. El-Shahat and M. Kandil, "Antioxidant capacity of follicular fluid in relation to follicular size and stage of estrous cycle in buffaloes," Theriogenology, vol. 77, no. 8, 2012.
[62] R. Behl and R. S. Pandey, "FSH induced stimulation of catalase activity in goat granulosa cells in vitro," Animal Reproduction Science, vol. 70, no. 3-4, pp. 215-221, 2002.

[63] R. K. Parshad and S. S. Guraya, "Changes in catalase activity during follicular growth, atresia and luteinization in rat ovary," Indian Journal of Experimental Biology, vol. 31, no. 2, pp. 109-111, 1993.

[64] S. Angelucci, D. Ciavardelli, F. di Giuseppe et al., "Proteome analysis of human follicular fluid," Biochimica et Biophysica Acta (BBA)-Proteins and Proteomics, vol. 1764, no. 11, 2006.

[65] C. M. Combelles, E. A. Holick, L. J. Paolella, D. C. Walker, and $\mathrm{Q}$. Wu, "Profiling of superoxide dismutase isoenzymes in compartments of the developing bovine antral follicles," Reproduction, vol. 139, no. 5, pp. 871-881, 2010.

[66] H. F. Hozyen, H. H. Ahmed, G. E. Essawy, and S. I. Shalaby, "Seasonal changes in some oxidant and antioxidant parameters during folliculogenesis in Egyptian buffalo," Animal Reproduction Science, vol. 151, no. 3-4, 2014.

[67] B. Du, K. Takahashi, G. M. Ishida, K. Nakahara, H. Saito, and H. Kurachi, "Usefulness of intraovarian artery pulsatility and resistance indices measurement on the day of follicle aspiration for the assessment of oocyte quality," Fertility and Sterility, vol. 85, no. 2, pp. 366-370, 2006.

[68] L. L. Espey, "Current status of the hypothesis that mammalian ovulation is comparable to an inflammatory reaction," Biology of Reproduction, vol. 50, no. 2, pp. 233-238, 1994.

[69] R. L. Stouffer, F. Xu, and D. M. Duffy, "Molecular control of ovulation and luteinization in the primate follicle," Frontiers in Bioscience, vol. 12, no. 1, pp. 297-307, 2007.

[70] A. Rizzo, M. T. Roscino, F. Binetti, and R. L. Sciorsci, "Roles of reactive oxygen species in female reproduction," Reproduction in Domestic Animals, vol. 47, no. 2, pp. 344-352, 2012.

[71] Y. S. Park, S. Y. You, S. Cho et al., "Eccentric localization of catalase to protect chromosomes from oxidative damages during meiotic maturation in mouse oocytes," Histochemistry and Cell Biology, vol. 146, no. 3, pp. 281-288, 2016.

[72] J. L. Tilly and K. I. Tilly, "Inhibitors of oxidative stress mimic the ability of follicle-stimulating hormone to suppress apoptosis in cultured rat ovarian follicles," Endocrinology, vol. 136, no. 1, pp. 242-252, 1995.

[73] B. R. Rueda, K. I. Tilly, T. R. Hansen, P. B. Hoyer, and J. L. Tilly, "Expression of superoxide dismutase, catalase and glutathione peroxidase in the bovine corpus luteum: evidence supporting a role for oxidative stress in luteolysis," Endocrine, vol. 3, no. 3, pp. 227-232, 1995.

[74] C. Sim and D. L. Denlinger, "Catalase and superoxide dismutase-2 enhance survival and protect ovaries during overwintering diapause in the mosquito Culex pipiens," Journal of Insect Physiology, vol. 57, no. 5, pp. 628-634, 2011.

[75] N. Nagan and R. A. Zoeller, "Plasmalogens: biosynthesis and functions," Progress in Lipid Research, vol. 40, no. 3, pp. 199229, 2001.

[76] E. G. Prates, S. P. Alves, C. C. Marques et al., "Fatty acid composition of porcine cumulus oocyte complexes (COC) during maturation: effect of the lipid modulators trans-10, cis-12 conjugated linoleic acid (t10,c12 CLA) and forskolin," In Vitro Cellular \& Developmental Biology. Animal, vol. 49, no. 5, pp. 335-345, 2013.

[77] S. Karnati and E. Baumgart-Vogt, "Peroxisomes in mouse and human lung: their involvement in pulmonary lipid 
metabolism," Histochemistry and Cell Biology, vol. 130, no. 4, pp. 719-740, 2008.

[78] S. Wang, Role of peroxisomes in granulosa cells, follicular development and steroidogenesis in the mouse ovary, [Ph. D. thesis], Justus Liebig University Giessen, 2018.

[79] L. L. Wu, K. R. Dunning, X. Yang et al., "High-fat diet causes lipotoxicity responses in cumulus-oocyte complexes and decreased fertilization rates," Endocrinology, vol. 151, no. 11, pp. 5438-5445, 2010.

[80] X. Yang, K. R. Dunning, L. L. Wu et al., "Identification of perilipin-2 as a lipid droplet protein regulated in oocytes during maturation," Reproduction, Fertility, and Development, vol. 22, no. 8, pp. 1262-1271, 2010.

[81] A. K. Hajra, L. K. Larkins, A. K. Das, N. Hemati, R. L. Erickson, and O. A. MacDougald, "Induction of the Peroxisomal Glycerolipid-synthesizing Enzymes during Differentiation of 3T3-L1 Adipocytes:," The Journal of Biological Chemistry, vol. 275, no. 13, pp. 9441-9446, 2000.

[82] M. Dieuaide-Noubhani, S. Asselberghs, G. P. Mannaerts, and V. Veldhoven, "Evidence that multifunctional protein 2, and not multifunctional protein 1 , is involved in the peroxisomal $\beta$-oxidation of pristanic acid," The Biochemical Journal, vol. 325, no. 2, pp. 367-373, 1997.

[83] J. K. Reddy and G. P. Mannaerts, "Peroxisomal lipid metabolism,” Annual Review of Nutrition, vol. 14, no. 1, pp. 343-370, 1994.

[84] R. G. Sturmey, P. J. O'Toole, and H. J. Leese, "Fluorescence resonance energy transfer analysis of mitochondrial:lipid association in the porcine oocyte," Reproduction, vol. 132, no. 6, pp. 829-837, 2006.

[85] K. R. Dunning, K. Cashman, D. L. Russell, J. G. Thompson, R. J. Norman, and R. L. Robker, "Beta-oxidation is essential for mouse oocyte developmental competence and early embryo Development1," Biology of Reproduction, vol. 83, no. 6, pp. 909-918, 2010.

[86] S. M. Downs, J. L. Mosey, and J. Klinger, "Fatty acid oxidation and meiotic resumption in mouse oocytes," Molecular Reproduction and Development, vol. 76, no. 9, pp. 844-853, 2009.

[87] M. Paczkowski, E. Silva, W. B. Schoolcraft, and R. L. Krisher, "Comparative importance of fatty acid beta-oxidation to nuclear maturation, gene expression, and glucose metabolism in mouse, bovine, and porcine cumulus oocyte Complexes1," Biology of Reproduction, vol. 88, no. 5, p. 111, 2013.

[88] W. F. Marei, D. C. Wathes, and A. A. Fouladi-Nashta, "Impact of linoleic acid on bovine oocyte maturation and embryo development," Reproduction, vol. 139, no. 6, pp. 979-988, 2010.

[89] N. Sugino, A. Karube-Harada, T. Taketani, A. Sakata, and Y. Nakamura, "Withdrawal of ovarian steroids stimulates prostaglandin F2.ALPHA. production through nuclear Factor-.KAPPA.B activation via oxygen radicals in human endometrial stromal cells: potential relevance to menstruation," The Journal of Reproduction and Development, vol. 50, no. 2, pp. 215-225, 2004.

[90] I. A. Buhimschi, W. B. Kramer, C. S. Buhimschi, L. P. Thompson, and C. P. Weiner, "Reduction-oxidation (redox) state regulation of matrix metalloproteinase activity in human fetal membranes," American Journal of Obstetrics and Gynecology, vol. 182, no. 2, pp. 458-464, 2000.

[91] U. Diczfalusy, B. F. Kase, S. E. Alexson, and I. Bjorkhem, "Metabolism of prostaglandin F2 alpha in Zellweger syn- drome. Peroxisomal beta-oxidation is a major importance for in vivo degradation of prostaglandins in humans," The Journal of Clinical Investigation, vol. 88, no. 3, pp. 978-984, 1991.

[92] C. Stocco, "Aromatase expression in the ovary: hormonal and molecular regulation,” Steroids, vol. 73, no. 5, pp. 473-487, 2008.

[93] S. L. Sanders and R. L. Stouffer, "Localization of steroidogenic enzymes in macaque luteal tissue during the menstrual cycle and simulated early pregnancy: immunohistochemical evidence supporting the two-cell model for estrogen production in the primate corpus Luteum1," Biology of Reproduction, vol. 56, no. 5, pp. 1077-1087, 1997.

[94] M. Vitti, G. di Emidio, M. di Carlo et al., "Peroxisome proliferator-activated receptors in female reproduction and fertility," PPAR Research, vol. 2016, Article ID 4612306, 12 pages, 2016.

[95] J. Berger and D. E. Moller, "The mechanisms of action of PPARs," Annual Review of Medicine, vol. 53, no. 1, pp. 409-435, 2002.

[96] J. C. Huang, "The role of peroxisome proliferator-activated receptors in the development and physiology of gametes and preimplantation embryos," PPAR Research, vol. 2008, Article ID 732303, 7 pages, 2008.

[97] E. Barlaka, A. Gorbe, R. Gaspar, J. Paloczi, P. Ferdinandy, and A. Lazou, "Activation of PPAR $\beta / \delta$ protects cardiac myocytes from oxidative stress-induced apoptosis by suppressing generation of reactive oxygen/nitrogen species and expression of matrix metalloproteinases," Pharmacological Research, vol. 95-96, pp. 102-110, 2015.

[98] P. Gervois, I. P. Torra, J. C. Fruchart, and B. Staels, "Regulation of lipid and lipoprotein metabolism by PPAR activators," Clinical Chemistry and Laboratory Medicine, vol. 38, no. 1, pp. 3-11, 2000.

[99] C. M. Komar, O. Braissant, W. Wahli, and T. E. Curry Jr., "Expression and localization of PPARs in the rat ovary during follicular development and the periovulatory period," Endocrinology, vol. 142, no. 11, pp. 4831-4838, 2001.

[100] C. M. Komar and T. E. Curry Jr., "Localization and expression of messenger RNAs for the peroxisome proliferatoractivated receptors in ovarian tissue from naturally cycling and pseudopregnant Rats1," Biology of Reproduction, vol. 66, no. 5, pp. 1531-1539, 2002.

[101] P. Froment, S. Fabre, J. Dupont et al., "Expression and functional role of peroxisome proliferator-activated Receptor- $\gamma$ in ovarian folliculogenesis in the Sheep1," Biology of Reproduction, vol. 69, no. 5, pp. 1665-1674, 2003.

[102] C. M. Komar, "Peroxisome proliferator-activated receptors (PPARs) and ovarian function - implications for regulating steroidogenesis, differentiation, and tissue remodeling," Reproductive Biology and Endocrinology, vol. 3, no. 1, p. 41, 2005.

[103] T. Viergutz, B. Loehrke, R. Poehland, F. Becker, and W. Kanitz, "Relationship between different stages of the corpus luteum and the expression of the peroxisome proliferator-activated receptor gamma protein in bovine large lutein cells," Journal of Reproduction and Fertility, vol. 118, no. 1, pp. 153-161, 2000.

[104] Y. Cui, K. Miyoshi, E. Claudio et al., "Loss of the Peroxisome Proliferation-activated Receptor gamma (PPAR $\gamma$ ) Does Not Affect Mammary Development and Propensity for Tumor 
Formation but Leads to Reduced Fertility," The Journal of Biological Chemistry, vol. 277, no. 20, pp. 17830-17835, 2002.

[105] A. Kurzynska, M. Bogacki, K. Chojnowska, and I. Bogacka, "Peroxisome proliferator activated receptor ligands affect progesterone and 17beta-estradiol secretion by porcine corpus luteum during early pregnancy," Journal of Physiology and Pharmacology, vol. 65, no. 5, pp. 709-717, 2014.

[106] W. L. Miller and R. J. Auchus, “The molecular biology, biochemistry, and physiology of human steroidogenesis and its disorders," Endocrine Reviews, vol. 32, no. 1, pp. 81-151, 2011.

[107] S. Hogenboom, J. J. Tuyp, M. Espeel, J. Koster, R. J. Wanders, and H. R. Waterham, "Phosphomevalonate kinase is a cytosolic protein in humans," Journal of Lipid Research, vol. 45, no. 4, pp. 697-705, 2004.

[108] S. Hogenboom, J. J. Tuyp, M. Espeel, J. Koster, R. J. Wanders, and H. R. Waterham, "Mevalonate kinase is a cytosolic enzyme in humans," Journal of Cell Science, vol. 117, no. 4, pp. 631-639, 2004.

[109] P. L. Faust and W. J. Kovacs, "Cholesterol biosynthesis and ER stress in peroxisome deficiency," Biochimie, vol. 98, pp. 75-85, 2014.

[110] M. M. Magalhaes and M. C. Magalhaes, "Peroxisomes in adrenal steroidogenesis," Microscopy Research and Technique, vol. 36, no. 6, pp. 493-502, 1997.

[111] Y. Suzuki, T. Orii, M. Takiguchi, M. Mori, M. Hijikata, and T. Hashimoto, "Biosynthesis of membrane polypeptides of rat liver Peroxisomes1," Journal of Biochemistry, vol. 101, no. 2, pp. 491-496, 1987.

[112] A. M. Gallegos, B. P. Atshaves, S. M. Storey et al., "Gene structure, intracellular localization, and functional roles of sterol carrier protein-2," Progress in Lipid Research, vol. 40, no. 6, pp. 498-563, 2001.

[113] G. A. Keller, T. J. Scallen, D. Clarke, P. A. Maher, S. K. Krisans, and S. J. Singer, "Subcellular localization of sterol carrier protein-2 in rat hepatocytes: its primary localization to peroxisomes," The Journal of Cell Biology, vol. 108, no. 4, pp. 1353-1361, 1989.

[114] A. van Amerongen, M. van Noort, J. R. van Beckhoven, F. F. Rommerts, J. Orly, and K. W. Wirtz, "The subcellular distribution of the nonspecific lipid transfer protein (sterol carrier protein 2) in rat liver and adrenal gland," Biochimica et Biophysica Acta, vol. 1001, no. 3, pp. 243-248, 1989.

[115] S. Mendis-Handagama, M. L. Chamindrani, P. A. Watkins et al., "Luteinizing hormone causes rapid and transient changes in rat Leydig cell peroxisome volume and intraperoxisomal sterol carrier protein-2 content," Endocrinology, vol. 127, no. 6, pp. 2947-2954, 1990.

[116] G. V. Vahouny, R. Chanderbhan, B. J. Noland et al., "Sterol carrier protein2. Identification of adrenal sterol carrier protein2 and site of action for mitochondrial cholesterol utilization.," The Journal of Biological Chemistry, vol. 258, no. 19, pp. 11731-11737, 1983.

[117] S. M. Mendis-Handagama, R. F. Aten, P. A. Watkins, T. J. Scallen, and H. R. Berhman, "Peroxisomes and sterol carrier protein-2 in luteal cell steroidogenesis: a possible role in cholesterol transport from lipid droplets to mitochondria," Tissue \& Cell, vol. 27, no. 5, pp. 483-490, 1995.

[118] R. Chanderbhan, B. J. Noland, T. J. Scallen, and G. V. Vahouny, "Sterol carrier protein2. Delivery of cholesterol from adrenal lipid droplets to mitochondria for pregneno- lone synthesis.," The Journal of Biological Chemistry, vol. 257, no. 15, pp. 8928-8934, 1982.

[119] M. P. Reinhart, "Intracellular sterol trafficking," Experientia, vol. 46, no. 6, pp. 599-611, 1990.

[120] G. V. Vahouny, R. Chanderbhan, A. Kharroubi, B. J. Noland, A. Pastuszyn, and T. J. Scallen, "Sterol carrier and lipid transfer proteins," Advances in Lipid Research, vol. 22, pp. 83-113, 1987.

[121] K. W. Wirtz, G. T. Snoek, T. W. Gadella, P. A. van Paridon, and P. J. Somerharju, "Properties and possible function of phosphatidylinositol-transfer proteins," Biotechnology and Applied Biochemistry, vol. 12, no. 5, pp. 485-488, 1990.

[122] H. Rennert, A. Amsterdam, J. T. Billheimer, and J. F. Strauss 3rd., "Regulated expression of sterol carrier protein 2 in the ovary: a key role for cyclic AMP," Biochemistry, vol. 30, no. 47, pp. 11280-11285, 1991.

[123] W. H. Trzeciak, E. R. Simpson, T. J. Scallen, G. V. Vahouny, and M. R. Waterman, "Studies on the synthesis of sterol carrier protein-2 in rat adrenocortical cells in monolayer culture. Regulation by ACTH and dibutyryl cyclic 3',5'-AMP.," The Journal of Biological Chemistry, vol. 262, no. 8, pp. 37133717, 1987.

[124] G. Moeller and J. Adamski, "Multifunctionality of human $17 \beta$-hydroxysteroid dehydrogenases," Molecular and Cellular Endocrinology, vol. 248, no. 1-2, pp. 47-55, 2006.

[125] G. Moeller and J. Adamski, "Integrated view on 17betahydroxysteroid dehydrogenases," Molecular and Cellular Endocrinology, vol. 301, no. 1-2, pp. 7-19, 2009.

[126] M. C. Magalhaes and M. M. Magalhaes, "Ultrastructural alterations produced in rat adrenal by aminoglutethimide," A stereologic and cytochemical study. Endocrinology, vol. 90, no. 2, pp. 444-452, 1972.

[127] G. Mazzocchi, C. Robba, P. Rebuffat, A. S. Belloni, and G. G. Nussdorfer, "Effects of the hypolipidemic drug nafenopin on the zona fasciculata of the rat adrenal cortex: a correlated biochemical and stereological study," The Anatomical Record, vol. 204, no. 3, pp. 245-254, 1982.

[128] G. Mazzocchi, P. Rebuffat, A. S. Belloni, G. Gottardo, V. Meneghelli, and G. G. Nussdorfer, "Effects of mevinolin, an inhibitor of cholesterol synthesis, on the morphological and functional responses of rat adrenal zona fasciculata to a prolonged treatment with 4-aminopyrazolo-pyrimidine," The Anatomical Record, vol. 221, no. 3, pp. 700-706, 1988.

[129] S. M. Mendis-Handagama, B. R. Zirkin, and L. L. Ewing, "Comparison of components of the testis interstitium with testosterone secretion in hamster, rat, and guinea pig testes perfused in vitro," The American Journal of Anatomy, vol. 181, no. 1, pp. 12-22, 1988.

[130] S. P. Klinken and P. M. Stevenson, "Changes in enzyme activities during the artificially stimulated transition from follicular to luteal cell types in rat ovary," European Journal of Biochemistry, vol. 81, no. 2, pp. 327-332, 1977.

[131] V. H. Black and J. J. Russo, "Stereological analysis of the guinea pig adrenal: effects of dexamethasone and ACTH treatment with emphasis on the inner cortex," The American Journal of Anatomy, vol. 159, no. 1, pp. 85-120, 1980.

[132] J. J. Russo and V. H. Black, "Hormone-dependent changes in peroxisomal enzyme activity in guinea pig adrenal.," The Journal of Biological Chemistry, vol. 257, no. 7, pp. 38833889, 1982. 
[133] J. E. Fortune, "Ovarian follicular growth and development in Mammals1," Biology of Reproduction, vol. 50, no. 2, pp. 225232, 1994.

[134] R. C. Tuckey, Z. Kostadinovic, and P. M. Stevenson, "Ferredoxin and cytochrome P-450 scc $_{\text {concentrations in granulosa }}$ cells of porcine ovaries during follicular cell growth and luteinization," Journal of Steroid Biochemistry, vol. 31, no. 2, pp. 201-205, 1988.

[135] S. G. Sligar, J. D. Lipscomb, P. G. Debrunner, and I. C. Gunsalus, "Superoxide anion production by the autoxidation of cytochrome P450 cam," Biochemical and Biophysical Research Communications, vol. 61, no. 1, pp. 290-296, 1974.

[136] R. C. Tuckey and H. Kamin, "The oxyferro complex of adrenal cytochrome P-450scc. Effect of cholesterol and intermediates on its stability and optical characteristics.," The Journal of Biological Chemistry, vol. 257, no. 16, pp. 9309-9314, 1982.

[137] K. Goda, J. Chu, T. Kimura, and A. P. Schaap, "Cytochrome c enhancement of singlet molecular oxygen production by the $\mathrm{NADPH}$ - dependent adrenodoxin reductase-adrenodoxin system: The role of singlet oxygen in damaging adrenal mitochondrial membranes," Biochemical and Biophysical Research Communications, vol. 52, no. 4, pp. 1300-1306, 1973.

[138] H. R. Behrman and R. F. Aten, "Evidence that hydrogen peroxide blocks hormone-sensitive cholesterol transport into mitochondria of rat luteal cells," Endocrinology, vol. 128, no. 6, pp. 2958-2966, 1991.

[139] N. Sugino, S. Takiguchi, S. Kashida, A. Karube, Y. Nakamura, and H. Kato, "Superoxide dismutase expression in the human corpus luteum during the menstrual cycle and in early pregnancy," Molecular Human Reproduction, vol. 6, no. 1, pp. 19-25, 2000.

[140] G. A. Keller, T. G. Warner, K. S. Steimer, and R. A. Hallewell, " $\mathrm{Cu}, \mathrm{Zn}$ superoxide dismutase is a peroxisomal enzyme in human fibroblasts and hepatoma cells," Proceedings of the National Academy of Sciences, vol. 88, no. 16, pp. 73817385, 1991.

[141] K. Kananen, M. Markkula, E. Rainio, J. G. Su, A. J. Hsueh, and I. T. Huhtaniemi, "Gonadal tumorigenesis in transgenic mice bearing the mouse inhibin alpha-subunit promoter/ simian virus $\mathrm{T}$-antigen fusion gene: characterization of ovarian tumors and establishment of gonadotropin-responsive granulosa cell lines," Molecular Endocrinology, vol. 9, no. 5, pp. 616-627, 1995.

[142] R. Brigelius-Flohe, C. Muller, J. Menard, S. Florian, K. Schmehl, and K. Wingler, "Functions of GI-GPx: lessons from selenium-dependent expression and intracellular localization," BioFactors, vol. 14, no. 1-4, pp. 101-106, 2001.

[143] H. J. Forman and M. Torres, "Reactive oxygen species and cell signaling," American Journal of Respiratory and Critical Care Medicine, vol. 166, supplement_1, pp. S4-S8, 2002.

[144] Q. Li, S. Sanlioglu, S. Li, T. Ritchie, L. Oberley, and J. F. Engelhardt, "GPx-1 gene delivery modulates NF $\kappa$ B activation following diverse environmental injuries through a specific subunit of the IKK complex," Antioxidants \& Redox Signaling, vol. 3, no. 3, pp. 415-432, 2001.

[145] A. Agarwal and S. S. Allamaneni, "Role of free radicals in female reproductive diseases and assisted reproduction," Reproductive Biomedicine Online, vol. 9, no. 3, pp. 338-347, 2004.

[146] I. Fridovich, "Superoxide radical and superoxide dismutases," Annual Review of Biochemistry, vol. 64, no. 1, pp. 97-112, 1995.
[147] A. Nenicu, Influence of peroxisomes on development, maturation and adult functions of the testis, Justus-Liebig-Universität Gießen, 2010.

[148] D. M. Stocco, J. Wells, and B. J. Clark, “The effects of hydrogen peroxide on steroidogenesis in mouse Leydig tumor cells," Endocrinology, vol. 133, no. 6, pp. 2827-2832, 1993.

[149] H. R. Behrman and S. L. Preston, "Luteolytic actions of peroxide in rat ovarian cells," Endocrinology, vol. 124, no. 6, pp. 2895-2900, 1989.

[150] T. Endo, R. F. Aten, L. Leykin, and H. R. Behrman, "Hydrogen peroxide evokes antisteroidogenic and antigonadotropic actions in human granulosa luteal cells," The Journal of Clinical Endocrinology and Metabolism, vol. 76, no. 2, pp. 337342, 1993.

[151] T. Diemer, J. A. Allen, K. H. Hales, and D. B. Hales, "Reactive oxygen disrupts mitochondria in MA-10 tumor Leydig cells and inhibits steroidogenic acute regulatory (StAR) protein and steroidogenesis," Endocrinology, vol. 144, no. 7, pp. 2882-2891, 2003.

[152] I. P. Artemenko, D. Zhao, D. B. Hales, K. H. Hales, and C. R. Jefcoate, "Mitochondrial Processing of Newly Synthesized Steroidogenic Acute Regulatory Protein (StAR), but Not Total StAR, Mediates Cholesterol Transfer to Cytochrome P450 Side Chain Cleavage Enzyme in Adrenal Cells," The Journal of Biological Chemistry, vol. 276, no. 49, pp. 4658346596, 2001.

[153] E. Baumgart, I. Vanhorebeek, M. Grabenbauer et al., "Mitochondrial Alterations Caused by Defective Peroxisomal Biogenesis in a Mouse Model for Zellweger Syndrome (PEX5 Knockout Mouse)," The American Journal of Pathology, vol. 159, no. 4, pp. 1477-1494, 2001.

[154] P. G. Barth, J. Gootjes, H. Bode, P. Vreken, C. B. Majoie, and R. J. Wanders, "Late onset white matter disease in peroxisome biogenesis disorder," Neurology, vol. 57, no. 11, pp. 19491955, 2001.

[155] A. B. Moser, M. Rasmussen, S. Naidu et al., "Phenotype of patients with peroxisomal disorders subdivided into sixteen complementation groups," The Journal of Pediatrics, vol. 127, no. 1, pp. 13-22, 1995.

[156] M. Baes and P. P. Van Veldhoven, "Generalised and conditional inactivation of Pex genes in mice," Biochimica et Biophysica Acta, vol. 1763, no. 12, pp. 1785-1793, 2006.

[157] C. Rodemer, T. P. Thai, B. Brugger et al., "Inactivation of ether lipid biosynthesis causes male infertility, defects in eye development and optic nerve hypoplasia in mice," Human Molecular Genetics, vol. 12, no. 15, pp. 1881-1895, 2003.

[158] S. Huyghe, H. Schmalbruch, K. de Gendt et al., "Peroxisomal multifunctional protein 2 is essential for lipid homeostasis in Sertoli cells and male fertility in mice," Endocrinology, vol. 147, no. 5, pp. 2228-2236, 2006.

[159] C. Y. Fan, J. Pan, R. Chu et al., "Hepatocellular and Hepatic Peroxisomal Alterations in Mice with a Disrupted Peroxisomal Fatty Acyl-coenzyme A Oxidase Gene," The Journal of Biological Chemistry, vol. 271, no. 40, pp. 24698-24710, 1996.

[160] L. A. Horrocks and Y. K. Yeo, "Health benefits of docosahexaenoic acid (DHA)," Pharmacological Research, vol. 40, no. 3, pp. 211-225, 1999.

[161] E. E. Birch, D. R. Hoffman, R. Uauy, D. G. Birch, and C. Prestidge, "Visual acuity and the essentiality of docosahexaenoic acid and arachidonic acid in the diet of term infants," Pediatric Research, vol. 44, no. 2, pp. 201-209, 1998. 
[162] M. Martínez, E. Vázquez, M. T. García-Silva et al., "Therapeutic effects of docosahexaenoic acid ethyl ester in patients with generalized peroxisomal disorders," The American Journal of Clinical Nutrition, vol. 71, no. 1, pp. 376S-385S, 2000.

[163] M. T. Noguer and M. Martinez, "Visual follow-up in peroxisomal-disorder patients treated with docosahexaenoic acid ethyl ester," Investigative Ophthalmology \& Visual Science, vol. 51, no. 4, pp. 2277-2285, 2010.

[164] A. M. Paker, J. S. Sunness, N. H. Brereton et al., "Docosahexaenoic acid therapy in peroxisomal diseases: results of a double-blind, randomized trial," Neurology, vol. 75, no. 9, pp. 826-830, 2010.

[165] A. B. Moser, J. Borel, A. Odone et al., "A new dietary therapy for adrenoleukodystrophy: biochemical and preliminary clinical results in 36 patients," Annals of Neurology, vol. 21, no. 3, pp. 240-249, 1987.

[166] K. Tanaka, T. Shimizu, Y. Ohtsuka, Y. Yamashiro, and K. Oshida, "Early dietary treatments with Lorenzo's oil and docosahexaenoic acid for neurological development in a case with Zellweger syndrome," Brain \& Development, vol. 29, no. 9, pp. 586-589, 2007.

[167] Y. Arai, Y. Kitamura, M. Hayashi, K. Oshida, T. Shimizu, and Y. Yamashiro, "Effect of dietary Lorenzo's oil and docosahexaenoic acid treatment for Zellweger syndrome," Congenital Anomalies, vol. 48, no. 4, pp. 180-182, 2008.

[168] P. Aubourg, C. Adamsbaum, M. C. Lavallard-Rousseau et al., "A two-year trial of oleic and erucic acids ("Lorenzo's oil") as treatment for adrenomyeloneuropathy," The New England Journal of Medicine, vol. 329, no. 11, pp. 745-752, 1993.

[169] B. M. van Geel, J. Assies, E. B. Haverkort et al., "Progression of abnormalities in adrenomyeloneuropathy and neurologically asymptomatic X-linked adrenoleukodystrophy despite treatment with "Lorenzo's oil"," Journal of Neurology, Neurosurgery, and Psychiatry, vol. 67, no. 3, pp. 290-299, 1999.

[170] E. C. de Vet and H. van den Bosch, "Alkyl-dihydroxyacetonephosphate synthase," Cell Biochemistry and Biophysics, vol. 32, no. 1-3, pp. 117-121, 2000.

[171] N. E. Braverman and A. B. Moser, "Functions of plasmalogen lipids in health and disease," Biochimica et Biophysica Acta, vol. 1822, no. 9, pp. 1442-1452, 2012.

[172] R. D. Holmes, G. N. Wilson, and A. K. Hajra, "Peroxisomal enzyme deficiency in the Conradi-Hunerman form of chondrodysplasia punctata," The New England Journal of Medicine, vol. 316, no. 25, p. 1608, 1987.

[173] A. K. Das, R. D. Holmes, G. N. Wilson, and A. K. Hajra, "Dietary ether lipid incorporation into tissue plasmalogens of humans and rodents," Lipids, vol. 27, no. 6, pp. 401-405, 1992.

[174] G. N. Wilson, R. G. Holmes, J. Custer et al., "Zellweger syndrome: diagnostic assays, syndrome delineation, and potential therapy," American Journal of Medical Genetics, vol. 24, no. 1, pp. 69-82, 1986.

[175] R. Zhang, L. Chen, S. Jiralerspong, A. Snowden, S. Steinberg, and N. Braverman, "Recovery of PEX1-Gly843Asp peroxisome dysfunction by small-molecule compounds," Proceedings of the National Academy of Sciences of the United States of America, vol. 107, no. 12, pp. 5569-5574, 2010.

[176] K. Berendse, M. S. Ebberink, L. IJlst, B. T. Poll-The, R. J. Wanders, and H. R. Waterham, "Arginine improves peroxisome functioning in cells from patients with a mild peroxisome biogenesis disorder," Orphanet Journal of Rare Diseases, vol. 8, no. 1, p. 138, 2013.
[177] H. Wei, S. Kemp, M. C. McGuinness, A. B. Moser, and K. D. Smith, "Pharmacological induction of peroxisomes in peroxisome biogenesis disorders," Annals of Neurology, vol. 47, no. 3, pp. 286-296, 2000.

[178] A. Imamura, T. Tsukamoto, N. Shimozawa et al., "Temperature-sensitive phenotypes of peroxisome-assembly processes represent the milder forms of human peroxisomebiogenesis disorders," American Journal of Human Genetics, vol. 62, no. 6, pp. 1539-1543, 1998.

[179] N. Shimozawa, Y. Suzuki, Z. Zhang et al., "Nonsense and temperature-sensitive mutations in PEX13 are the cause of complementation group $\mathrm{H}$ of peroxisome biogenesis disorders," Human Molecular Genetics, vol. 8, no. 6, pp. 1077-1083, 1999.

[180] N. Cartier, S. Hacein-Bey-Abina, C. C. Bartholomae et al., "Lentiviral hematopoietic cell gene therapy for X-linked adrenoleukodystrophy," Methods in Enzymology, vol. 507, pp. 187-198, 2012.

[181] M. G. Toscano, Z. Romero, P. Munoz, M. Cobo, K. Benabdellah, and F. Martin, "Physiological and tissuespecific vectors for treatment of inherited diseases," Gene Therapy, vol. 18, no. 2, pp. 117-127, 2011.

[182] E. M. Sokal, F. Smets, A. Bourgois et al., "Hepatocyte transplantation in a 4-year-old girl with peroxisomal biogenesis disease: technique, safety, and metabolic follow-up1," Transplantation, vol. 76, no. 4, pp. 735-738, 2003.

[183] L. Van Maldergem, A. B. Moser, M. F. Vincent et al., "Orthotopic liver transplantation from a living-related donor in an infant with a peroxisome biogenesis defect of the infantile Refsum disease type," Journal of Inherited Metabolic Disease, vol. 28, no. 4, pp. 593-600, 2005.

[184] H. Y. Lian, Y. Gao, G. Z. Jiao et al., "Antioxidant supplementation overcomes the deleterious effects of maternal restraint stress-induced oxidative stress on mouse oocytes," Reproduction, vol. 146, no. 6, pp. 559-568, 2013.

[185] A. Tripathi, K. V. PremKumar, A. N. Pandey et al., "Melatonin protects against clomiphene citrate-induced generation of hydrogen peroxide and morphological apoptotic changes in rat eggs," European Journal of Pharmacology, vol. 667, no. 1-3, pp. 419-424, 2011.

[186] H. Tamura, A. Takasaki, I. Miwa et al., "Oxidative stress impairs oocyte quality and melatonin protects oocytes from free radical damage and improves fertilization rate," Journal of Pineal Research, vol. 44, no. 3, pp. 280-287, 2008.

[187] O. G. Eryilmaz, A. Devran, E. Sarikaya, F. N. Aksakal, L. Mollamahmutoglu, and N. Cicek, "Melatonin improves the oocyte and the embryo in IVF patients with sleep disturbances, but does not improve the sleeping problems," Journal of Assisted Reproduction and Genetics, vol. 28, no. 9, pp. 815820, 2011.

[188] A. S. Batioglu, U. Sahin, B. Gurlek, N. Ozturk, and E. Unsal, "The efficacy of melatonin administration on oocyte quality," Gynecological Endocrinology, vol. 28, no. 2, pp. 91-93, 2012.

[189] M. Liu, Y. Yin, X. Ye et al., "Resveratrol protects against ageassociated infertility in mice," Human Reproduction, vol. 28, no. 3, pp. 707-717, 2013.

[190] Y. Jiang, Z. Zhang, L. Cha et al., "Resveratrol plays a protective role against premature ovarian failure and prompts female germline stem cell survival," International Journal of Molecular Sciences, vol. 20, no. 14, p. 3605, 2019.

[191] H. L. Jiang, L. Q. Cao, and H. Y. Chen, "Protective effects ROS up-regulation on premature ovarian failure by suppressing 
ROS-TERT signal pathway," European Review for Medical and Pharmacological Sciences, vol. 22, no. 19, pp. 61986204, 2018.

[192] J. Mier-Cabrera, T. Aburto-Soto, S. Burrola-Méndez et al., "Women with endometriosis improved their peripheral antioxidant markers after the application of a high antioxidant diet," Reproductive Biology and Endocrinology, vol. 7, no. 1, p. 54, 2009.

[193] J. Mier-Cabrera, M. Genera-Garcia, J. De la Jara-Diaz, O. Perichart-Perera, F. Vadillo-Ortega, and C. HernandezGuerrero, "Effect of vitamins $\mathrm{C}$ and E supplementation on peripheral oxidative stress markers and pregnancy rate in women with endometriosis," International Journal of Gynaecology and Obstetrics, vol. 100, no. 3, pp. 252-256, 2008.

[194] I. A. Cotgreave, "N-acetylcysteine: pharmacological considerations and experimental and clinical applications," Advances in Pharmacology, vol. 38, pp. 205-227, 1996.

[195] G. S. Kelly, "Clinical applications of N-acetylcysteine," Alternative Medicine Review, vol. 3, no. 2, pp. 114-127, 1998.

[196] A. F. Amin, O. M. Shaaban, and M. A. Bediawy, “ $N$-acetyl cysteine for treatment of recurrent unexplained pregnancy loss," Reproductive Biomedicine Online, vol. 17, no. 5, pp. 722-726, 2008.

[197] G. S. Aseervatham, T. Sivasudha, R. Jeyadevi, and D. Arul Ananth, "Environmental factors and unhealthy lifestyle influence oxidative stress in humans-an overview," Environmental Science and Pollution Research International, vol. 20, no. 7, pp. 4356-4369, 2013. 